\title{
LITOESTRATIGRAFÍA DEL GRUPO TECOCOYUNCA (JURÁSICO MEDIO) EN EL ÁREA DEL RÍO ÑUMÍ (CERCANÍAS DE TLAXIACO), OAXACAY CONSIDERACIONES SOBRE LA DISTRIBUCIÓN REGIONAL DE SU BIOTA
}

\author{
LITHOSTRATIGRAPHY OF THE TECOCOYUNCA GROUP(MIDDLE JURASSIC) \\ IN THE ÑUMÍ RIVER AREA(VICINITY OF TLAXIACO), OAXACA, AND \\ CONSIDERATIONS ABOUT THE REGIONAL DISTRIBUTION OF THE BIOTA
}

\author{
Raúl S. Carrasco-Ramírez ${ }^{1}$, Ismael Ferrusquía-Villafranca ${ }^{2 *}$, \\ Blanca E. Buitrón-Sánchez² \& José E. Ruiz-González² \\ ${ }^{1}$ Constitución 228 A, Montenegro, Santa Catarina, Nuevo León, México 66179 \\ ${ }^{2}$ Instituto de Geología, Universidad Nacional Autónoma de México, Circuito \\ de la Investigación s/n, Ciudad Universitaria, Coyoacán, México, D.F., 04510 \\ *Autor para contacto: ismaelfv@unam.mx
}

(Recibido: 28/01/2016; aceptado: 04/05/2016)

\begin{abstract}
The Jurassic lithostratigraphy of the Mixteca Region is relatively well known however, the system on which it is based includes somewhat deficient formational descriptions (e.g. vagueness, characterization by fossil content, insufficient cartographic discrimination). In order to contribute to correct such deficiency, we undertook a detailed study of the Río Numí area, vicinity of Tlaxiaco, where the Middle Jurassic units that make up the Tecocoyunca Group display their attributes, thus allowing to supplement the formational descriptions. It was found that locally, the Tecocoyunca Group includes in the lower part the associated Formations Zorrillo/Taberna (Early to Late Bajocian), consisting of $287 \mathrm{~m}$ of carbonaceous siltstone, mudstone and subarkosic very fine-grained sandstone and siltstone; this composite unit bears pelecypods and continental plants, as well as two carbon zones; it is interpreted that they were part of a delta complex. These associated formations conformably underlie the Simón Formation (Middle-Late Bathonian), it consists of $\sim 270 \mathrm{~m}$ of subarkoses and siltstone set in thin to thick strata; it is interpreted as a transitional deposit. This unit concordantly underlies the Otatera Formation (Late Bathonian), consisting of $\sim 170 \mathrm{~m}$ of pelecypod coquina with intercalations of spathitic limestone strata; it is regarded as shallow neritic deposit with a subordinate beach component. This unit concordantly underlies the Yucuñuti Formation (Middle Callovian), constituted by $\sim 118 \mathrm{~m}$ of fine-grained sandstone, coquina and biomicrite that bear pelecypods and gastropods; it is interpreted as a transitional to shallow
\end{abstract}


neritic deposit. This unit is unconformably overlain the Oxfordian Limestone with "Cidaris," which is no part of this group. The Tecocoyunca Group Biota includes a typical Middle Jurassic flora, whose taxa are widely distributed in Mexico's central and southern regions, as well as in northern Central America; and a paleofauna constituted by Middle Jurassic mollusks common throughout the Mixteca Region. The biota as a whole discloses a warm and humid climate regime. Finally, it is thought that the detailed descriptions of the formations making up the Tecocoyunca Group are in fact an advance in the redefinition of the Mixtec Region's Middle Jurassic units.

Keywords: Mexico, Oaxaca, Middle Jurassic, Tecocoyunca Group, Lithostratigraphy, Paleontology.

RESUMEN: La litoestratigrafía jurásica de la Región Mixteca es relativamente bien conocida, sin embargo, el esquema en que se basa incluye descripciones formacionales un tanto deficientes (e.g. vaguedad, caracterización por contenido fósil, delimitación cartográfica insuficiente). Con el propósito de contribuir a subsanar esta deficiencia, realizamos un estudio detallado del área Ñumí, cercanías de Tlaxiaco, donde las unidades mesojurásicas integrantes del Grupo Tecocoyunca despliegan sus atributos, permitiendo así suplementar las descripciones formacionales. Se encontró que el Grupo Tecocoyunca localmente incluye en la parte inferior a las Formaciones Asociadas Zorrillo/Taberna (Bajociano Temprano-Tardío inicial), constituidas por $\sim 287 \mathrm{~m}$ de limolitas carbonosas, lodolitas y subarcosas, porta pelecípodos y plantas terrestres, así como dos zonas de carbón; se les interpreta como parte de un complejo deltaico. Estas formaciones subyacen en concordancia a la Formación Simón (Batoniano Medio-Tardío), integrada por $\sim 270 \mathrm{~m}$ de subarcosas y limolitas dispuestas en estratos delgados y gruesos; se le considera un depósito transicional. Esta unidad subyace en concordancia a la Formación Otatera (Batoniano tardío), consiste en $\sim 170 \mathrm{~m}$ de coquinas de pelecípodos con intercalaciones de estratos calcáreos de intraespatita; se le interpreta como un depósito nerítico somero, con un componente subordinado de playa. Esta unidad subyace concordantemente a la Formación Yucuñuti (Calloviano Medio), constituida por $\sim 118 \mathrm{~m}$ de areniscas finas, coquinas, limolitas y biomicritas que portan pelecípodos y gasterópodos; se le interpreta como un depósito transicional a nerítico somero. A esta unidad le sobreyace en discordancia la Caliza con "Cidaris" del Oxfordiano, que no forma parte de este grupo. La biota del Grupo Tecocoyunca incluye una típica paleoflora mesojurásica, cuyos taxa se encuentran ampliamente distribuidos en la región centro-meridional de México y septentrional de Centroamérica; así como una paleofauna integrada por moluscos mesojurásicos comunes en la Región Mixteca. La biota en conjunto denota un clima regional cálido y húmedo. Finalmente, se considera que la descripción detallada de las formaciones que constituyen al Grupo Tecocoyunca, es de facto un avance en la redefinición de las unidades mesojurásicas de la Región Mixteca.

Palabras clave: México, Oaxaca, Jurásico Medio, Grupo Tecocoyunca, Litostratigrafía, Paleontología.

\section{INTRODUCCIÓN}

La Región Mixteca (noreste de Guerrero, noroeste de Oaxaca y sur de Puebla) ha atraído el interés de muchos geólogos (e.g. Wieland 1909; 1914-1916; 1926, Burckhardt, 1927; Guzmán, 1950; Erben, 1956; Cortés-Obregón et al., 1957; Alencáster, 1963; Ochoterena-Fuentes, 1960; Pérez-Ibarguëngoitia et al., 1965; Ojeda-Rivera, 1975; Ortega-Gutiérrez, 1978; Westermann, 1983, 1984; López-Ticha, 1985; Morán-Zenteno et al., 1993; Meneses-Rocha et al., 1994; OrtizMartínez et al., 2013). Destacan por sus contribuciones a la estratigrafía y paleontología de esta región el de Burckhardt (1927), extensa monografía donde se describe e ilustra la fauna fósil, sentando así la base paleontológica del Jurásico
Medio de México, y el de Erben (1956), donde se establece el fundamento estratigráfico del Jurásico en esta región, incluyendo entre otras las siguientes unidades litoestratigráficas: Grupo Tecocoyunca, constituido por las Formaciones Zorrillo, Taberna, Simón, Otatera y Yucuñuti. Sin embargo, cabe destacar que las descripciones litológicas presentadas por este autor, son algo imprecisas, ya que algunas de ellas sólo son reconocibles por la fauna que portan y otras no están discriminadas cartográficamente, sino sólo en secciones/perfiles sin un control topográfico preciso.

A pesar de ello, el esquema estratigráfico de Erben (1956), es decir, las unidades propuestas por él, se han utilizado extensamente en descripciones geológicas de esta región; tal es el caso del Grupo Tecocoyunca (Jurásico Medio), 
el cual ha sido identificado ampliamente en la Mixteca. Por tal motivo, se consideró conveniente estudiar este grupo en al área del río Ñumí, en las cercanías de Tlaxiaco, Oaxaca, la cual está relativamente próxima al área Diquiyú, región de Tezoatlán (Fig. 1). Los afloramientos de este grupo presentan características estratigráficas y paleontológicas muy claras, que permitieron complementar las descripciones originales de las unidades litoestratigráficas jurásicas y así contribuir a un mejor conocimiento sobre la geología de la región. Además, en esta área se encuentran algunos yacimientos mesojurásicos de carbón, conocidos tempranamente (ver Ramírez, 1882; Birkinbine, 1911; Cortés-Obregón et al., 1957), los cuales confieren a esta área un gran interés económico potencial.

Área de estudio. El área yace a ambos lados del río Ñumí, en la Región Mixteca, noroeste de Oaxaca, forma un rectángulo dispuesto NE-SW, de $\sim 10 \mathrm{~km}$ de longitud, $4 \mathrm{~km}$ de anchura, y una superficie de $\sim 40 \mathrm{~km}^{2}$ dispuesta entre las coordenadas extremas $17^{\circ} 16^{\prime}-17^{\circ} 22^{\prime} \mathrm{N}$ y $97^{\circ} 41^{\prime}$ $97^{\circ} 46^{\prime} \mathrm{W}$ (Fig. 1) así como entre los 2000-2200 msnm; el relieve es abrupto, y el poblado principal es Santiago Nundichi, al cual se llega por un camino de terracería que parte de la Carretera Federal 125, a unos cinco kilómetros al NE de Tlaxiaco.

\section{MATERIAL Y MÉTODOS}

El material cartográfico utilizado incluye la Carta Topográfica Tlaxiaco E14D34, escala 1:50 000 (INEGI, 2000); la Carta GeológicoMinera Tlaxiaco E14D34 escala 1:50 000 (SGM, 2000), y la Carta Geológica Oaxaca E14-9 escala 1:250 000 (INEGI, 1994). Se aplicó el método habitual del trabajo geológico (Finkl, 1988). Se realizó la búsqueda y análisis de la literatura pertinente, para conocer y evaluar la información disponible, e integrar la información cartográfica, en un mapa preliminar que sirviese de base para el trabajo de campo. Este consistió en recorridos geológicos para verificar contactos de unidades litoestratigráficas, levantar secciones estratigráficas y estructurales. Las descripciones de las unidades litoestratigráficas satisfacen lo establecido en el Código Estratigráfico Norteamericano NACSN (2005), versión en español (Barragán et al., 2010).

La descripciones litológicas y petrográficas se basan en las observaciones y fotografías de campo, así como en $\sim 80$ muestras líticas y $\sim 60$ láminas delgadas; la terminología petrográfica/ litológica es la de Folk (1974) y Boggs (2009). Las identificaciones taxonómicas se basan en $\sim 70$ ejemplares macroscópicos de invertebrados y plantas. Al final se trata la distribución de los taxa que constituyen la paleobiota de este grupo para enmarcarla en una perspectiva regional.

\section{RESULTADOS Y DISCUSIÓN}

\section{Litoestratigrafía}

\section{Grupo Tecocoyunca}

Con el nombre de Grupo Tecocoyunca, Erben (1956) designa una secuencia de areniscas, limolitas, lutitas carbonosas y calizas, que aflora ampliamente en la Región Mixteca, designando como localidad tipo la barranca homónima, situada entre Cualac y Huamuxtitlán, Guerrero (distante $\sim 150 \mathrm{~km}$ al oeste del área Numí), asignándolo al Jurásico Medio e indicando que estaba constituido por cinco Formaciones: Zorrillo, Taberna, Simón, Otatera, y Yucuñuti. Este autor también reconoció dichas unidades en el área de Diquiyú, región de Tezoatlán, la cual se ubica $\sim 70$ al Oeste del área estudiada. Destaca la gran similitud de la secuencia jurásica en ambas áreas, lo cual permitió complementar la descripción litológica de las unidades, con base en las observaciones en Ñumí.

En el área de estudio, el Grupo Tecocoyunca aflora extensamente a ambos lados del río Numí (Fig. 3), tiene un espesor aproximado de 800 $\mathrm{m}$; estructuralmente corresponde al flanco de un sinclinal de rumbo NNE-SSW e inclinado $\sim 35-80^{\circ}$ hacia el ESE; además está afectado por fallamiento normal dispuesto aproximadamente perpendicular al rumbo del flanco (Fig. 3). A continuación se describen las unidades litoestratigráficas que integran a este grupo. 


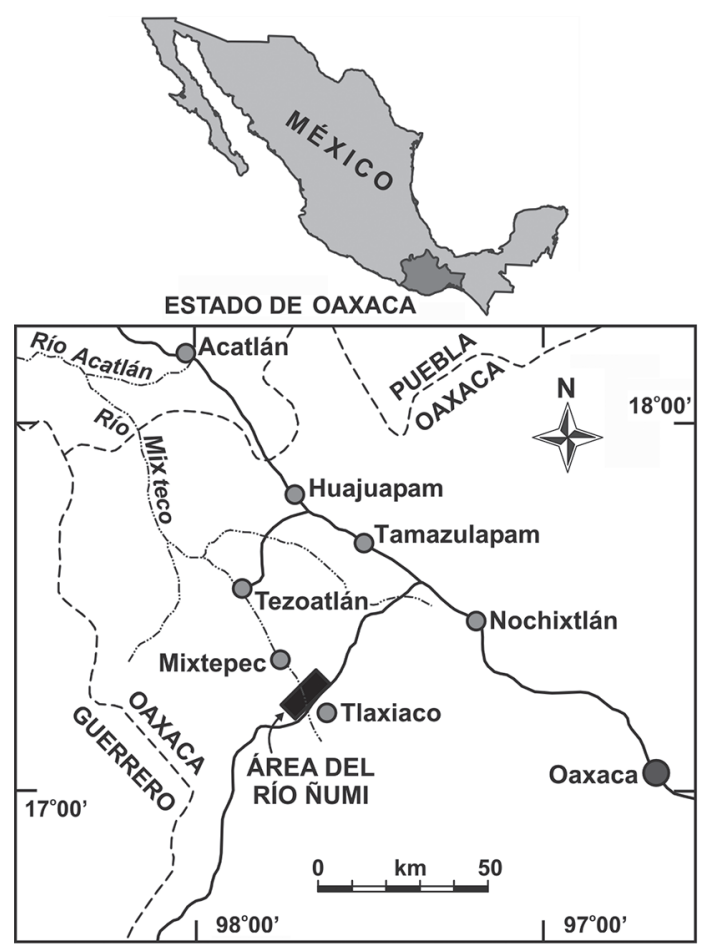

Fig. 1: Mapa de localización del área del Río Numí, cercanías de Tlaxiaco, Oaxaca.

\section{“Unidad” Zorrillo/Taberna}

Erben (1956) dio nombre a la Formación Zorrillo, tomándolo de la Loma del Zorrillo, localizada al este de San Juan Diquiyú, región de Tezoatlán, Oaxaca, designando a este lugar como Localidad Tipo, asignándole una edad bajociana temprana. Además Erben (1956) definió a la Formación Taberna, asignándole como Localidad Tipo la falda de la Loma de la Tierra Amarilla, en la ribera sur del Arroyo de la Taberna, al noroeste de San Juan Diquiyú, asignándole una edad mesobajociana a batoniana temprana.

La comparación de ambas definiciones, denota considerable parecido litológico, que aunado a la relación transicional que las asocia, dificulta enormemente su reconocimiento preciso fuera del área tipo. En estas condiciones, ha sido imposible reconocer objetivamente a estas unidades en la secuencia jurásica del área Numí. En consecuencia, se decidió asociarlas en un conjunto estratigráfico designado "Unidad” Zorrillo/
Taberna, sin discriminar cartográficamente dichas formaciones (Figs. 2 y 3). Esta "Unidad" aflora muy cerca de la ribera noroccidental del río Ñumí, y se extiende a los cuerpos litológicos y estratigráficamente similares que se encuentra fuera de esta zona en el área de estudio.

El contacto inferior es transicional con el Conglomerado Cualac y el superior también es transicional con la base de la Formación Simón. El espesor total de esta unidad es variable, sin embargo, un promedio obtenido de la información geológica superficial obtenida al realizar este estudio, es de 277 m. La Sección de Referencia fue medida en el Arroyo Yuticuani (Fig. 4A).

Litología: Las principales rocas de la "Unidad" Zorrillo/Taberna son limolitas arcillosas con material carbonoso (Figs. 5A, B, C y D), plantas e invertebrados fósiles. Su color varía de gris claro a gris oscuro, predominando el primero hacia la cima. La estratificación es en capas medianas a gruesas (30 a $40 \mathrm{~cm}$ de espesor); la parte superior consiste de una alternancia de lodolitas $\mathrm{y}$ areniscas.

Se identificó la presencia de dos zonas de carbón, una en la parte inferior y otra en la superior. Localmente, la parte inferior presenta nódulos ferruginosos. Las estructuras primarias principales incluyen estratificación convoluta, pistas y tubos de gusanos, diastratificación, laminaciones, estratificación gradacional normal y rizaduras. El contenido de fósiles es abundante e incluye plantas terrestres e invertebrados marinos.

Las zonas de carbón indican un ambiente pantanoso, donde concurrieron condiciones geográficas y tectónicas apropiadas para la acumulación de turba. La presencia de carbón en dos zonas, indica recurrencia de estas condiciones sedimentarias y tectónicas. A continuación se describen brevemente las tres variedades litológicas principales.

1) Limolita filarenítica carbonosa (Fig. 6A). Esta variedad constituye la mayor parte de las Formaciones Zorrillo-Taberna. Su descripción petrográfica consiste en granos clásticos que constituyen del 60 al 70\% del sedimento, su tamaño varía de limo fino a arena muy fina, dominando el limo mediano; los clastos son angulares y subangulares, su clasificación es mala a moderadamente buena; 


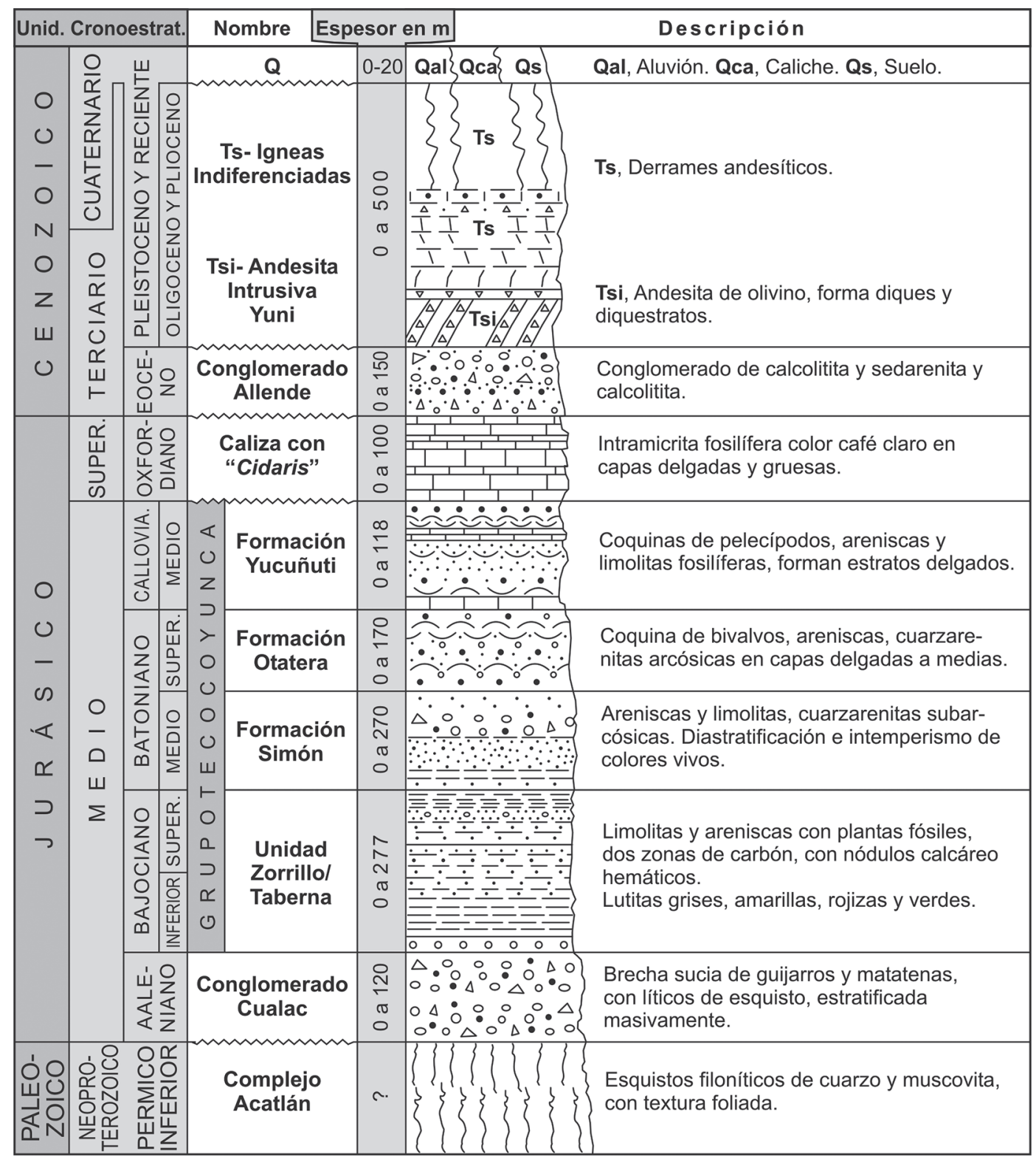

Fig. 2: Columna estratigráfica generalizada del Área del Río Numí.

algunos granos tienen distribución bimodal. La mayoría de los granos son de cuarzo (75\%); su forma varía de equidimensional a alargada; un $10 \%$ muestra extinción fuertemente ondulante, sugiriendo origen metamórfico. El resto de los granos de cuarzo muestra extinción recta o ligeramente ondulante, y contienen inclusiones escasas (vacuolas y/o microlitos dispuestos al azar). El feldespato, probablemente alcalino, forma el 5 al $10 \%$ de la fracción granular, la mayoría de ellos muestra alteración a arcilla.

La mica forma del 10 al 15\% de los granos, la variedad dominante es biotita de colores rojizo y azulado, muestra una orientación persistente, su tamaño varía de 40 a 60 micras. Existe también calcita $(\sim 1 \%)$, es de forma anhedral y 


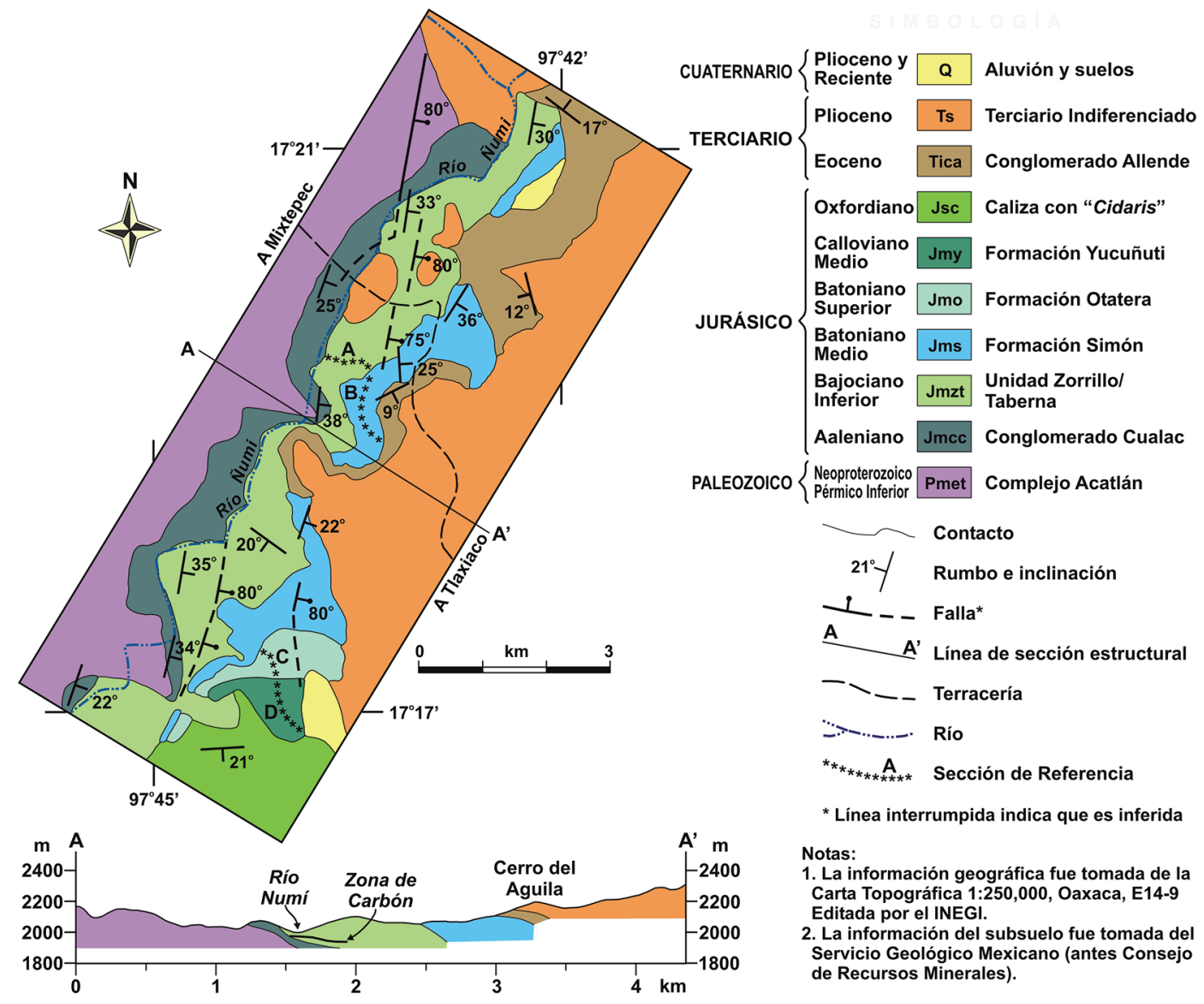

Fig. 3: Mapa geológico y sección estructural generalizada del área del río Numí, cercanías de Tlaxiaco.

origen secundario. El material carbonoso es escaso, e incluye palinomorfos y kerógeno (Enrique Martínez Hernández, comunicación personal). La matriz constituye del 30 al $40 \%$ de la roca, consiste principalmente en caolín, clorita, ?illita y ferromagnesianos no identificados (hiperstena?). La presencia de caolín y clorita se confirmó por Difracción de Rayos X (realizada en los Laboratorios del Consejo de Recursos Minerales, ahora Servicio Geológico Mexicano).

2) Lodolita cuarcítico-filarenítica (Fig. 6B). Consiste en material clástico dispuesto en una matriz arcillosa abundante (30 a 40\%). Los granos constituyen del 60 al 70\% del sedimento, su tamaño varía de limo mediano a arena muy fina, dominando el de limo grueso. La mayor parte de los granos son angulares y su clasificación es mala. La constitución mineralógica de esta variedad incluye principalmente cuarzo $(80-90 \%)$, los granos son alargados y en su mayoría tienen extinción recta, las inclusiones (microlitos) son raras. Los clastos de mica (10 a 20\%) presentan alteración muy homogénea, tienen forma irregular, su color es pardo rojizo y pardo azulado. La matriz está formada por arcilla no identificada y microcristales ?ferromagnesianos.

3) Arenisca mesogranuda cuarcítico-subarcósico-filarenítica (Fig. 6C). Los granos de cuarzo constituyen del 80 al $85 \%$ de la roca, su tamaño es el de la arena mediana. La mayoría son subredondeados, y su clasificación es moderada a buena; La forma de los granos es casi equidimensional a alargada; un tercio de ellos tiene extinción fuertemente ondulante y compuesta, el resto muestra 

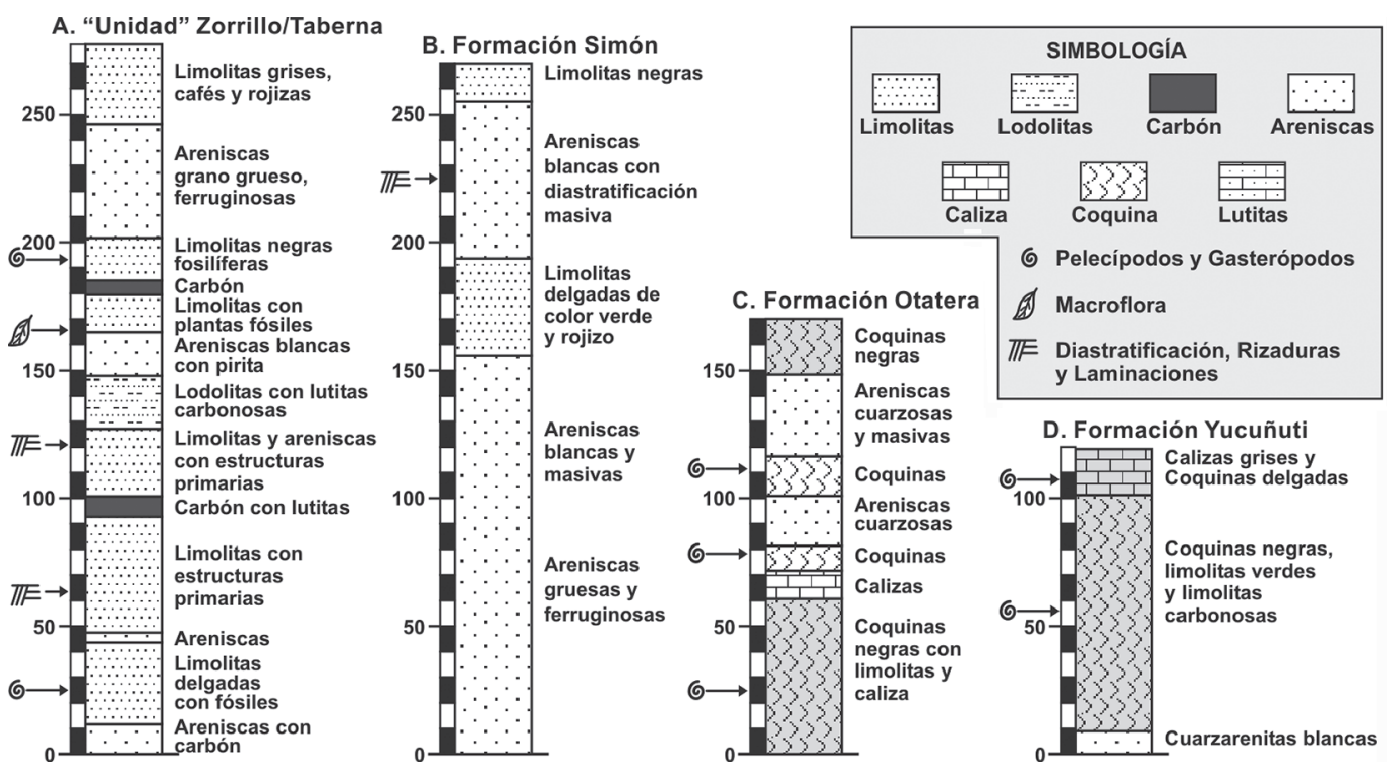

Fig. 4: Secciones principales de referencia de las formaciones que integran al Grupo Tecocoyunca.

extinción recta. Las inclusiones son escasas. Los clastos de feldespato (15 a 20\%) tienen forma irregular y están alterados a arcilla.

Ambiente de Depósito. Los rasgos sedimentológicos observados en la "Unidad" Zorrillo/Taberna (e.g. clastos de forma redondeada, clasificación moderada a buena, y configuración acordonada -i.e., de shoe string), sugiere que el depósito de estas unidades ocurrió en canales fluviales asociados a un complejo deltaico. La interpretación ambiental sugerida por la textura y otros atributos sedimentarios de las limolitas carbonosas, es la de un depósito transicional con influjo marino y fluvial. La materia orgánica relativamente abundante indica predominio de condiciones reductoras. En el caso de las lodolitas, el ambiente deposicional es similar; la presencia de algunos estratos de colores verdes y rosas en esta secuencia, sugiere oxidación subaérea ocasional. El espesor moderado de esta unidad, indica hundimiento leve y constante de la cuenca en condiciones de pasividad tectónica.

Por otro lado, la composición mineralógica, particularmente la presencia de cuarzo con extinción ondulante, y cantidades subordinadas de mica y arcilla, denota que el área-fuente era metamórfica y que muy probablemente haya sido el propio Complejo Acatlán, el cual incluye granito.

A su vez, la presencia de clastos feldespáticos argilizados, sugiere que el grado de intemperización sufrido por los sedimentos antes de ser depositados era muy alto; ello habría ocurrido con mayor facilidad en un clima cálido y húmedo en el áreafuente. Considerando la textura, particularmente la gran cantidad de sedimentos limo-arcillosos, sugiere que la distancia de transporte fuese moderada a lejana.

En suma, los rasgos observados permiten interpretar que en la "Unidad" Zorrillo/Taberna, está representado el registro de dos ambientes deposicionales: uno costero pantanoso (marisma) dominante y el otro fluvial más reducido; a su vez, ambos formaban parte de un complejo deltáico (ver Reineck y Singh, 1980; Howard y Reineck, 1981; Reading, 1996).

Además, la presencia de zonas de carbón en esta "Unidad," denota que se satisficieron estas condiciones (Stach, 1975; Tatsch, 1980): a) Hundimiento leve y constante, b) Protección del pantano por playas, barras de arena, isletas, entre otros, en contra de la inundación marina y mediante diques naturales en contra de la inundación de ríos, c) Un ambiente de 

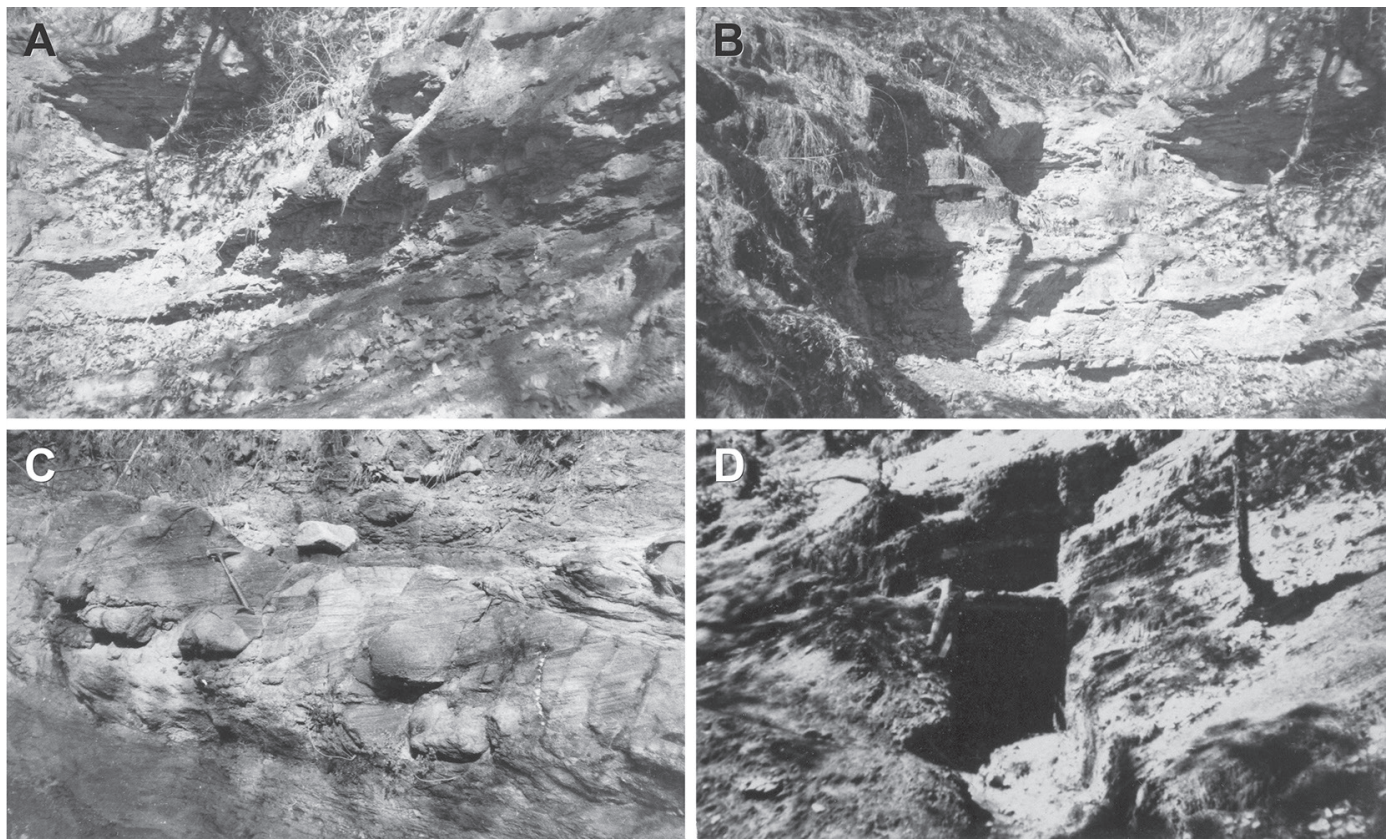

Fig. 5: Afloramientos de la "Unidad" Zorrillo/Taberna: A) Arroyo La Carbonera, muestra limolitas y areniscas de grano fino, camino a San Juan Mixtepec, km 6. B) Arroyo de Chicavanaicuche, muestra limolitas y areniscas de grano fino, idem, km 6. C) Puente del camino a Mixtepec, muestra limolitas, idem, km 8. D) Socabón que muestra limolitas carbonosas y laminaciones de carbón, idem, km 8.5 .

baja energía de la región continental y así mismo un aporte restringido de sedimentos fluviales, ya que de otra forma se interrumpiría la formación de la turba.

Contenido fósil. Cabe destacar que en la sección de Consideraciones sobre distribución de la Biota del Grupo Tecocoyunca, se precisan los taxa fósiles encontrados en ésta y las demás formaciones de este grupo, por ello no se presentan aquí. Los pelecípodos son cosmopolitas y denotan un ambiente marino o salobre. La macroflora continental encontrada, está integrada por taxa bien conocidos en la Región Mixteca, los cuales formaban parte de una vegetación continental de clima cálido húmedo (Wieland, 1914-1916; Silva-Pineda, 1970; Pearson, 1976; Ortiz-Martínez et al., 2013).

Edad. El alcance estratigráfico de los taxa fósiles procedentes del área del río Ñumí es así: El de los pelecípodos, abarca del Bajociano al Calloviano. Las plantas tienen un alcance estratigráfico aún mayor (Pearson, 1976; Sandoval y Westermann, 1986; Carrasco-Ramírez, 1999). Sin embargo, considerando que en el área de Mixtepec, muy próxima a la del río Ñumí, la Formación Taberna porta ammonites de edad bajociana (parte terminal del Bajociano Temprano a la parte inicial de Bajociano Tardío), se asigna a ese intervalo la edad de la "Unidad" Zorrillo/Taberna en esta área.

\section{Formación Simón}

Erben (1956) definió a esta unidad, seleccionando como Localidad Tipo el Arroyo del Simón en la Barranca del Carrizo, al noreste de San Juan Diquiyú, en la región de Tezoatlán, Oaxaca y le asignó una edad mesobatoniana.

En el área de estudio, la Formación Simón aflora principalmente en el Arroyo de Allende, sitio donde se midió la Sección de Referencia (Fig. 4B), así como en otros sitios. El contacto inferior es transicional con la "Unidad" Zorrillo/Taberna, y el superior es abrupto, aunque concordante, con la Formación Otatera. El espesor de la Formación Simón es de $\sim 270 \mathrm{~m}$. 

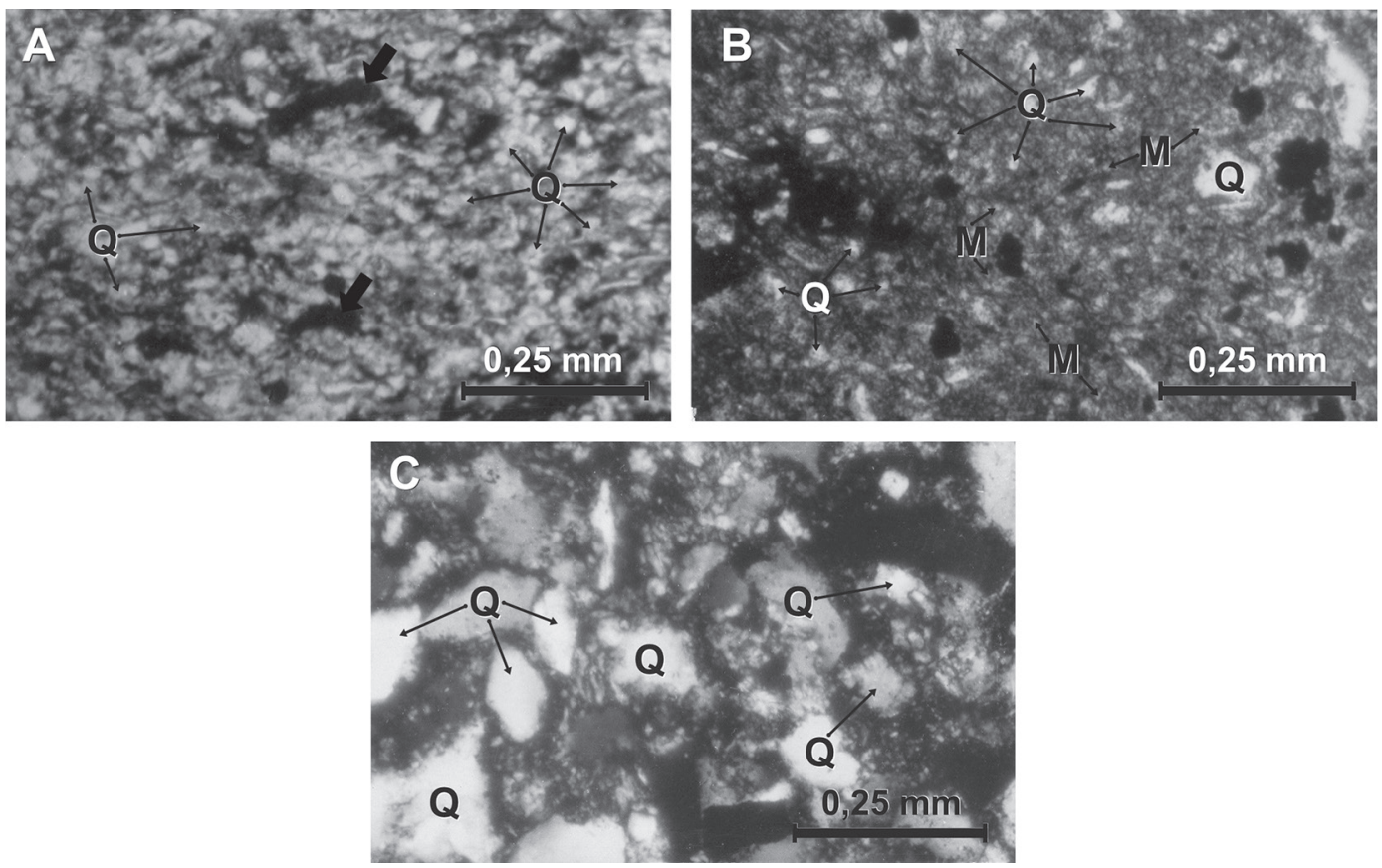

Fig. 6: Fotomicrografías de la "Unidad" Zorrillo/Taberna: A) Limolita filarenítica carbonosa en luz natural. Mesostasis de arcillas, los granos son principalmente de cuarzo (Q) y el material carbonoso se presenta en forma de pequeños lentes, señalados por las flechas. B) Lodolita cuarcítico-filarenítica en nícoles cruzados. Se observan principalmente arcillas y granos clásticos de cuarzo y mica (M). C) Arenisca mesogranuda cuarcítico-subarcósica filarenítica en nicoles cruzados. Predominancia de granos de cuarzo.

Litología: La parte principal de la Formación Simón es una arenisca subarcósica de grano medio a grueso, de color gris claro, estratificada en capas de 0,40 a $1,0 \mathrm{~m}$ y algunas de $1,5 \mathrm{~m}$ cuando aumenta el tamaño del grano, dichos estratos se intercalan en una secuencia dominada por capas delgadas de limolitas en colores rojizos y grises. En otras partes, se encuentra una zona de cuarzo-arenitas, cuyo espesor varía de 10 a $50 \mathrm{~m}$. Localmente, se presentan nódulos ferruginosos de color rojo. La estructura primaria dominante es la diastratificación (Figs. 7A-7B). A continuación se describen las variedades litológicas más comunes:

1) Arenisca mesogranuda cuarcítico-subarcósica. Esta variedad constituye la mayor parte de la formación (Fig. 8A). Los clastos forman el 95\% de la roca, los de cuarzo son abundantes ( $~ 80 \%)$, de éstos $\sim 25 \%$ muestra extinción ondulante $\mathrm{y}$ compuesta, lo cual sugiere un origen metamórfico, el resto muestra extinción recta. El feldespato ?alcalino (15 a 20\%) consiste de granos de forma irregular, que muestran fracturas muy desarrolladas. El grado de intemperización impidió una identificación más precisa. Se encuentran trazas de mica, principalmente biotita, y de minerales pesados (granate y turmalina); cabe destacar que éstos sugieren una procedencia de esquistos y pegmatitas (ver Folk, 1974). La matriz constituye el 5\% de la roca, está formada por limo mediano de ?mica argilizada, y arcilla; los minerales secundarios incluyen principalmente hematita y calcita, la cual rellena el espacio poroso, y funge como cementante.

2) Limolita filarenítica. Tiene textura de arcilla a limo fino, está constituida principalmente por cuarzo de extinción ondulante, calcedonia, mica argilizada y otros ferromagnesianos alterados; la matriz es arcillosa (Fig. 8B).

Ambiente de Depósito. La presencia de cuarzo de extinción ondulante, sugiere que el áreafuente debió incluir un componente metamórfico, tal vez el Complejo Acatlán. El cuarzo de extinción 

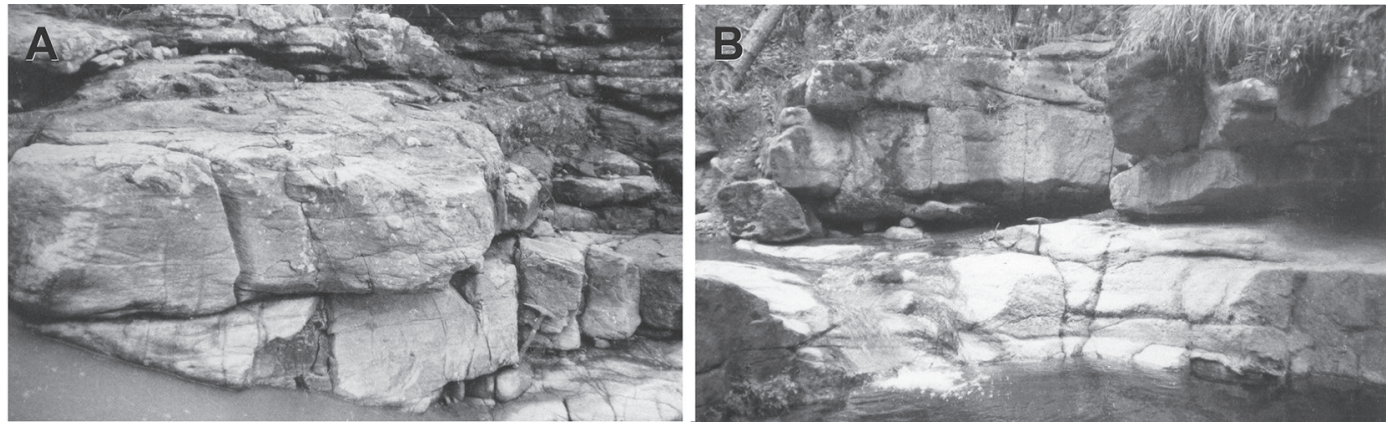

Fig. 7: Afloramientos de la Formación Simón donde se observan areniscas conglomeráticas con estructuras de diastratificación: A Arroyo de Allende, camino a Allende, km 11. B. Arroyo Yuní, camino a San Juan Mixtepec, km 6.

recta, indica que probablemente dicha área incluía también cuerpos ígneos (?granito). Por otro lado, el tamaño de los granos (limo fino) denota una distancia de transporte lejana a moderadamente lejana; ello aunado a la diastratificación, indica un ambiente fluvial (facies de planicie de inundación y facies de frente de delta); a su vez las coloraciones rojizas implican que los depósitos debieron estar periódicamente expuestos a oxidación subaérea (ver Reineck y Singh, 1980; Reading, 1996). En suma, al igual que las Formaciones Zorrillo/Taberna, la Formación Simón registra sedimentación de playa y fluvial, con dominio de la primera.

Edad. En ausencia de información objetiva paleontológica o radiométrica, la determinación de edad se apoya en las relaciones estratigráficas. La Formación Simón sobreyace transicionalmente a la "Unidad" Zorrillo/Taberna, cuya edad es bajociana, y subyace en concordancia a la Formación Otatera, de edad batoniana tardía
(Fig. 9). Entonces, la edad más probable para la Formación Simón es batoniana media a tardía.

\section{Formación Otatera}

Con este nombre Erben (1956) designó a la secuencia de rocas sedimentarias que tienen su localidad-tipo en la parte central y la salida septentrional de la Cañada Otatera del Río Rosario en la región de Tezoatlán, Oaxaca, asignándole una edad Batoniana tardía. En el área de estudio, esta unidad ocupa una extensión pequeña, expuesta en el Arroyo Doña Chona, situado en la parte sur del área (Fig. 3), y consiste en coquinas y areniscas, tiene $\sim 170 \mathrm{~m}$ de espesor (Figs. 2 y 9) y está interdigitada con la parte basal de la Formación Simón, y en la parte superior lo hace con la Formación Yucuñuti. La Sección de Referencia se midió en el Arroyo de Doña Chona (Fig. 4C).
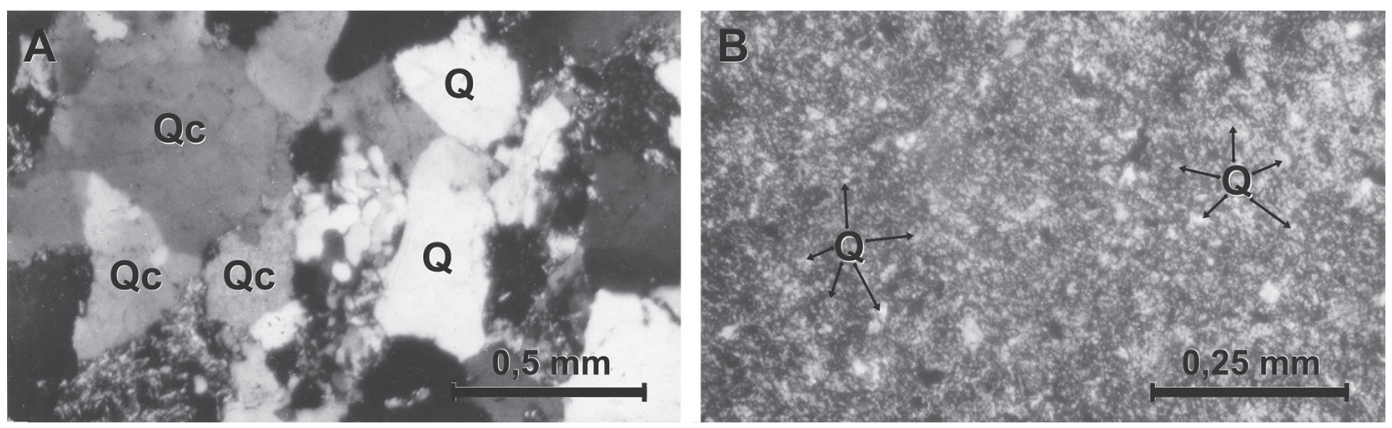

Fig. 8: Formación Simón, fotomicrografías: A) Arenisca mesogranuda cuarcítico-subarcósica en nicoles cruzados. Nótese la presencia de cuarzo compuesto (Qc) e ígneo en una mesotasis limo-arcillosa. B) Limolita filarenítica en luz paralela. Predominan microcristales del tamaño del limo fino y arcillas, con cuarzo disperso. 
Litología: La mayor parte de la Formación Otatera está constituida por estratos de coquina negra formada por Eocallista, Pleuromya, Crenotrapezium y ostréidos (Gryphaea), dispuestos en una matriz de espatita (Fig. 9). Las coquinas se encuentran intercaladas principalmente con capas calcáreas de color gris cremoso, en las que destacan cristales blanquecinos de calcita y fragmentos muy pequeños de conchas de color negro. El conjunto de coquinas con intercalaciones de caliza, está dispuesto en capas delgadas de 4 a $5 \mathrm{~cm}$. La parte superior de esta formación está constituida por arenisca de grano fino a grueso, dispuesta en estratos delgados a medianos (1 a $20 \mathrm{~cm}$ de espesor).

La Formación Otatera exhibe una modesta variabilidad lítica, la variedad más común es la espatita (Fig. 10). Ésta es submadura, calcarenítica, y contiene escasos fragmentos líticos (tamaño de arena gruesa), constituidos por toba ( $3 \%)$, subarcosa $(3 \%)$, cuarzo $(2 \%)$ y feldespato probablemente alcalino (2\%). Los granos están cementados por calcita espática $(\sim 90 \%)$, cuyos cristales miden 5 a 10 micras.

Ambiente de Depósito. Los rasgos sedimentarios de esta unidad, indican un ambiente marino somero (nerítico), con un aporte terrígeno esporádico, donde la movilidad del agua era capaz de erosionar la calcita microcristalina débilmente consolidada, y redepositarla como espatita. El material terrígeno denota un alto topográfico relativamente cercano. Cabe destacar que la mitad superior de esta unidad, consiste de arenisca (fina a crasogranular) dispuesta en capas delgadas que se hacen más gruesas con el tamaño del grano. Estas características sugieren que probablemente se depositaron en playas. Por otro lado, la presencia de coquinas indica sepultamiento continuo, que impidió la destrucción subaérea de las comunidades de pelecípodos; sólo el hundimiento relativamente rápido de la cuenca podría haber causado esto.

Contenido fósil. Incluye principalmente los pelecípodos Eocallista, Pleuromya, Crenotrapezium y Gryphaea, los cuales vivían en la zona de intermareas (Reineck y Singh, 1980); los esqueletos de estos moluscos al consolidarse formaron extensas coquina.

Edad. El alcance estratigráfico de los taxa reportados es amplio y no permite precisar la edad de esta formación a alguna época del Jurásico. Sin embargo, en el área de Tezoatlán, la Formación Otatera porta al ammonite Epistrenoceras paracontrarium, que es común en el Batoniano Tardío (Erben, 1956), lo cual permite asignarle esa edad a dicha formación.

\section{Formación Yucuñuti}

Erben (1956) designó Formación Yucuñuti, a la secuencia sedimentaria que aflora en el Arroyo homónimo (escogido como localidad tipo), situado al oriente de Santa María Yucuñuti, en la región de Tezoatlán, Oaxaca y la asignó al Calloviano.

En el área del río Ñumí, esta formación se ubica en la parte sur, particularmente en el Arroyo de Doña Chona, su extensión superficial es reducida (Fig. 3). En la base se interdigita con la Formación Otatera y en la cima subyace en discordancia a la Caliza con "Cidaris"; su espesor estimado es de $\sim 118$ m (Fig. 2). La Sección de Referencia se midió en el Arroyo mencionado (Fig. 4D).

Litología: La Formación Yucuñuti es una secuencia que se inicia con areniscas de grano fino, de colores blanquizcos y rosas (Fig. 11); la parte media es una alternancia de coquinas de ostreídos de color negro con limolitas de color gris claro, que exhiben numerosas pistas de gusanos. La parte superior está formada por capas medianas (20 a $30 \mathrm{~cm}$ ) de caliza fosilífera con intercalaciones de coquinas de Lucina, de color claro, en capas delgadas. Localmente acompañan a las coquinas algunas capas de ostreídos y gasterópodos tylostómidos. A continuación se describen las variedades más comunes:

1) Limolita cuarzoarenítica. Es una limolita gruesa, moderadamente clasificada, texturalmente submadura (Fig. 12A). La fracción granular forma el $\sim 70$ del volumen rocoso, está constituida por cuarzo de extinción recta $(\sim 80 \%)$ u ondulada (20\%); los granos miden $\sim 30 \mu \mathrm{m}$. Por otrol ado, la matriz es arcillosa (30\% de la roca); calcita espática rellena intersticios, microfracturas y funge como cementante.

2) Limolita cuarcítico-subarcósica. La roca está constituida por $70-80 \%$ de granos, dispuestos en una matriz arcillosa, moderadamente abundante 


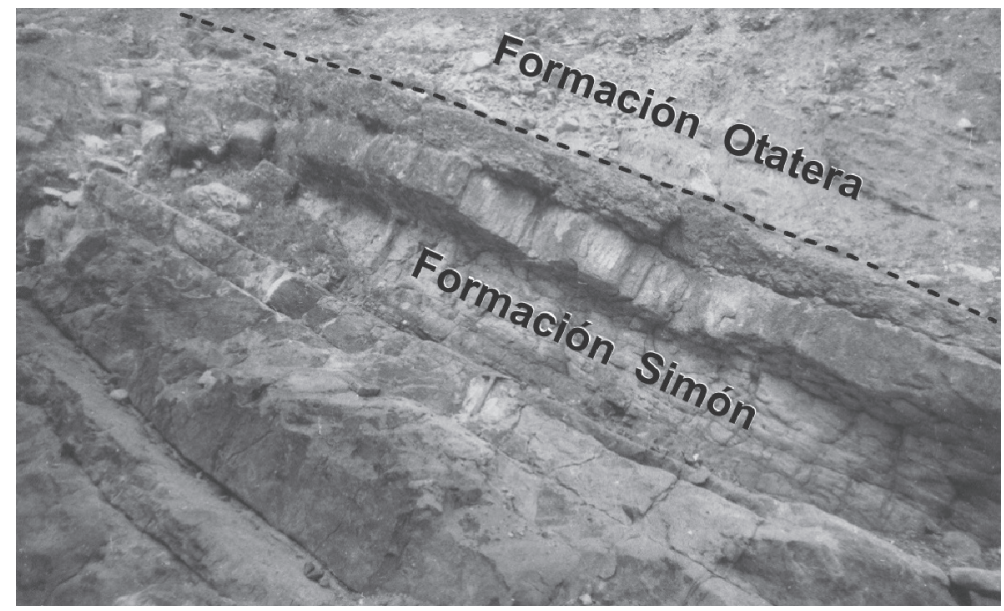

Fig. 9: Afloramiento que muestra el contacto de la Formación Simón con la Formación Otatera. Se observan areniscas infrayaciendo coquinas negras.

(20-30\% de la roca), lo cual le confiere una condición textural submadura (Fig. 12B). La fracción granular está constituida por cuarzo (70-80\%), los granos son angulosos, y de extinción recta (los de extinción ondulada son escasos), su tamaño es típicamente bimodal (10 micras y 40 micras). El resto de los granos (20 a 30\%) está formado por feldespato (?alcalino), los cristales están fracturados y algo alterados, su tamaño promedio es de 40 micras. La matriz consiste en microcristales de arcilla, mica y calcita. El tipo de cuarzo sugiere una fuente plutónica.
3) Bioclastita micrítico-cuarzolimosa. Esta es una variedad peculiar, consiste en bioclastos $(\sim 30 \%)$, clastos terrígenos fino-granudos $(\sim 30 \%)$ y matriz micrítica (40\%) (Fig. 12C). Los bioclastos principalmente son fragmentos de bivalvos. Los clastos terrígenos miden $\sim 20$ micras, incluyen cuarzo de extinción recta y ondulante, así como litoclastos (?ignimbrita).

Ambiente de Depósito. Las variedades líticas sugieren un ambiente transicional/marino somero, las variedades 1) y 3) corresponden a un ambiente nerítico, mientras que la variedad 2)

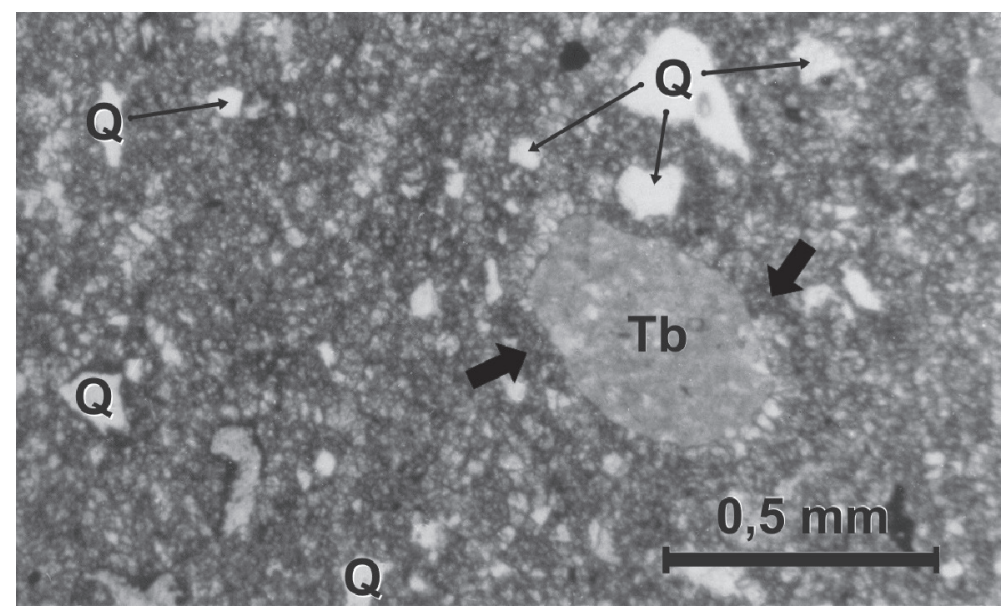

Fig. 10: Formación Otatera: Fotomicrografía en luz paralela. Destaca el grano tobáceo (Tb) rodeado por espatita (señalada por las flechas). 
indica un aporte terrígeno en una planicie con agua estancada. La composición mineralógica y la textura de las variedades líticas descritas, sugiere que el área-fuente debió consistir principalmente de cuerpos ígneos (?granito) y metamórficos, situados relativamente lejos de la cuenca sedimentaria.

Contenido Fósil. En la Formación Yucuñuti se recolectaron moluscos cosmopolitas de los géneros Lucina, Astarte, Vaugonia, Gryphaea, Eocallista, Crenotrapazium, Pleuromia, y Lima, los cuales denotan un ambiente marino o salobre.

Edad. El alcance estratigráfico amplio de los moluscos no permitió precisar la edad de esta formación y de su fauna. Sin embargo, en el área de Mixtepec, Carrasco-Ramírez (2003) encontró ammonites referibles al Calloviano medio; por otro lado, la correspondencia estratigráfica del área del río Numí con la de Mixtepec, permite asignar esta edad a la Formación Yucuñuti.

\section{Consideraciones sobre la distribución regional de la biota del Grupo Tecocoyunca}

La biota continental y marina estudiada está constituida principalmente por plantas cicadofitas filicales escasas y la marina por moluscos, entre ellos, pelecípodos y gasterópodos. Las plantas continentales en la "Unidad" Zorrillo/Taberna corresponden a fragmentos de frondas y conos de cicadofitas de las especies, Zamites oaxacensis Wieland, 1909 (Fig. 13A), Zamites lucerensis Wieland, 1909 (Fig. 13B), Williamsonia netzahualcoyotlii Wieland, 1909 (Fig. 13C) y Ptilophylum acutifolium Morris, 1840 (Fig. 13D). Estas especies fueron inicialmente descritas en otras localidades de la Mixteca Alta Oaxaqueña, por Wieland (1909, 1914-1916, 1926) y Delevoryas (1966, 1968, 1969). Posteriormente, han sido estudiadas por varios autores, entre ellos Delevoryas y Gould (1971); Delevoryas (1973); Delevoryas y Pearson, (1975); Silva-Pineda (1970, 1978a, 1978b); Pearson y Delevoryas, (1982); SilvaPineda (1984); Silva-Pineda et al., (1986a; 1986b) y Silva-Pineda (1990).
También, en las lutitas arcillosas de esta "Unidad" se hallaron moluscos pelecípodos identificados con Lucina cf. L. bellona D' Orbigny, 1850 (Fig. 13E), Astarte sp. D' Orbigny, 1850 (Fig. 13F), Vaugonia (Vaugonia) v-costata (Lycett) mexicana Alencáster, 1963 (Fig. 13G) y Trigonia (Indotrigonia) impressa Broderip, 1828 (Fig. $13 \mathrm{H})$, especies descritas para el Jurásico Medio de las regiones de El Rosario, Tezoatlán y Mixtepec, lugares que se localizan en el noroeste del Estado de Oaxaca y en la región de Cualac situada en el noreste del Estado de Guerrero (Alencáster, 1963).

Por su parte, de la Formación Simón se recolectaron fragmentos de plantas terrestres muy mal conservadas, probablemente referibles a cicadofitas ó filicales; también se encontraron restos escasos de bivalvos y gasterópodos marinos, no identificables. A su vez, de la Formación Otatera se recolectaron pelecípodos entre ellos, Eocallista imlayi Alencáster, 1963 (Figs. 13I, J), Pleuromya sp., Castillo y Aguilera, 1895 (Fig. 13K), Crenotrapezium hayami Alencáster, 1963 (Fig. 13L) y coquinas de ostréidos mal conservados. Estas especies han sido descritas anteriormente para el Jurásico Medio del noroeste de Oaxaca y noreste de Guerrero (Alencáster, 1963).

Finalmente, de la Formación Yucuñuti se recolectaron pelecípodos referibles a Lucina sp. (Fig. 13M), Lima (Plagiostoma) sp. (Fig. 13N), ya reportados por Alencáster (1963) para el Jurásico Medio del noroeste de Oaxaca y noreste de Guerrero, y Gryphaea mexicana Felix, 1891 (Fig. 13Ñ), descrita para el Jurásico Superior del Cerro de la Virgen, Tlaxiaco, Oaxaca (Felix, 1891); citada por Cragin (1905) para el Jurásico Superior de la Formación Malone, Texas, EUA y por Alencáster y Buitrón (1965) para la Caliza Chimeco en la región de Petlalcingo-Acatlán, en el Estado de Puebla. También se recolectaron escasos ejemplares de gasterópodos marinos mal conservados, probablemente tylostómidos. Estos taxa se han encontrado además en otras localidades mesojurásicas de Oaxaca, tales como Yucuquimi, noroeste del estado (Arambarri y Silva, 1987); San Andrés Yutatío (Silva-Pineda y Arambarri, 1991), y Chalcatongo, situado al suroeste del Estado de Oaxaca (Silva-Pineda, 1990). 


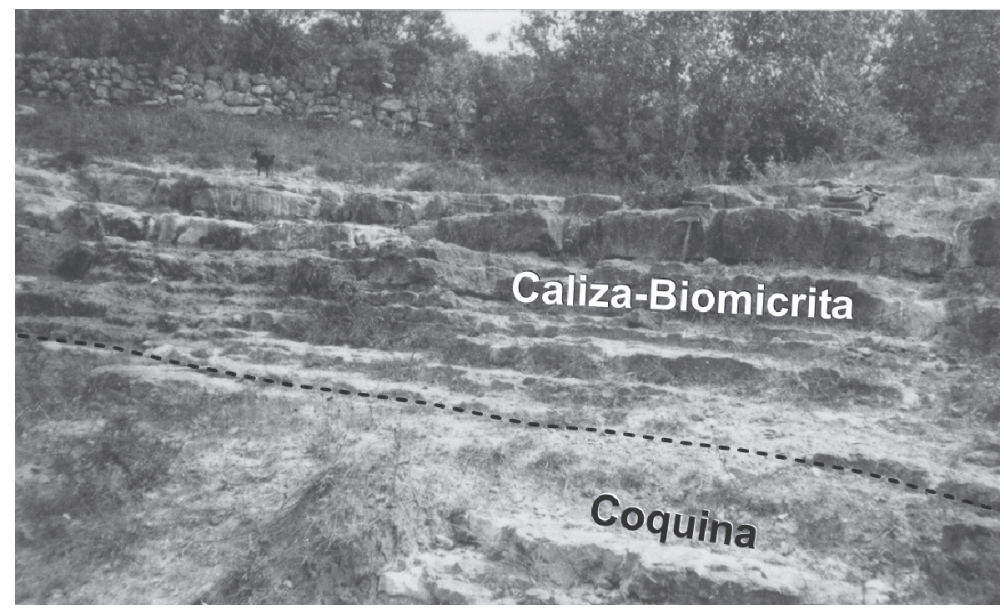

Fig. 11: Afloramiento de la Formación Yucuñuti. Estratos delgados de biomicritas y coquinas gris claro.

Cabe destacar que en Tezoatlán, al noroeste de Oaxaca (Silva-Pineda, 1970, 1990) se desarrolló una exuberante macroflora, donde predominaron las cicadofitas, principalmente representadas por Cycadeoidales y en menor proporción por Cicadales, asociadas a una amplia variedad de taxa menos abundantes, tales como filicales, equisetales, coniferofitas y otros de posición sistemática incierta (Delevoryas, 1966).

Se han encontrado diversas floras jurásicas afines en otras localidades de las regiones norte y sur de Puebla (Santa Cruz y Texcalapa),
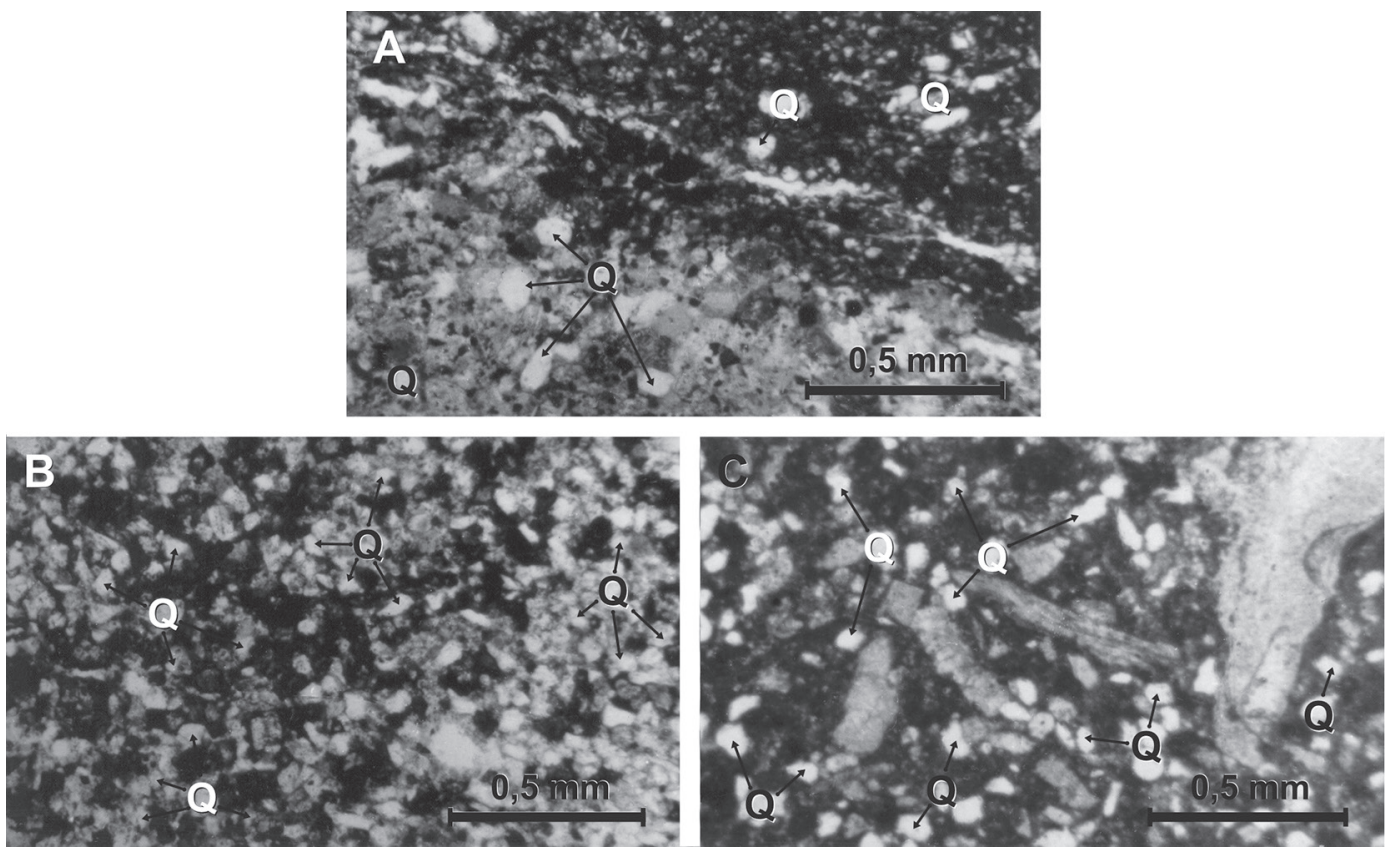

Fig. 12: Fotomicrografías de la Formación Yucuñuti: A) Limolita cuarzo-arenítica crasogranuda en luz paralela. Note que los granos de cuarzo son muy abundantes. B) Limolita cuarcítico-subarcósica en luz natural. Note que los granos de cuarzo tienen clasificación moderada. C) Bioclastita micrítica cuarcitica. Note los fragmentos de concha, los clastos de cuarzo -de extinción recta y ondulante- así como algunos litoclastos (?ignimbrita). 
así como en el noreste del Estado de Guerrero (Chilpancingo-Tlapa, Cualac); también se han encontrado en la región norte de Hidalgo (Tenango de San Agustín) y en el Estado de Chiapas (Cintalapa). Es particularmente interesante el hallazgo de elementos de esta flora en núcleos del subsuelo provenientes de Ciudad Victoria, Tamaulipas (Silva-Pineda y González-Gallardo, 1984 a,b; Silva-Pineda, 1990).

La flora mesojurásica de Oaxaca se correlaciona con floras contemporáneas de Cuba; región Antillana; Jalteva, Honduras y Centroamérica (Areces-Mallea, 1990; Delevoryas y Srivastava, 1981), mostrando así una amplia distribución paleobiogeográfica, lo cual confirma la gran semejanza genérica que la flora de Tlaxiaco, Oaxaca tiene con las floras europeas, descritas de Yorkshire, Inglaterra (Thomas, 1911), de Cerdeña, Italia (Scanu et al., 2012, 2013), de Caén, Francia (Saporta, 1891). En Asia fueron citadas de Rajmahal Hill, India (Feistmantel, 1877); en África (Webber, 1961; Ash, 1972) y de la región oeste de Australia (McCoy, 1847). Esto pone de manifiesto la existencia de una flora mesojurásica uniforme en casi todo el mundo, caracterizada por la presencia de cicadofitas bennetittales de los géneros Zamites, Otozamites y Ptilophyllum, así como filicales, latitudinalmente ubicadas entre los $45^{\circ}$ y $70^{\circ} \mathrm{N}$ (Vakhrameev, 1956; Vakhrameev y Lebedev, 1985). Dicha flora sugiere un clima cálido y húmedo, el cual concomitantemente debió extenderse de manera amplia durante esta edad.

\section{SUMARIO Y CONCLUSIONES}

1. El Grupo Tecocoyunca en el área del río Ñumí, región de Tlaxiaco, Oaxaca incluye en la parte inferior a las Formaciones Asociadas Zorrillo/Taberna de edad bajociana temprana (parte terminal)-bajociana tardía (parte inicial), sobreyacen transicionalmente al Conglomerado Cualac del Aaleniano, están constituidas por $\sim 287$ $\mathrm{m}$ de limolitas carbonosas, lodolitas y subarcosas, porta pelecípodos y plantas fósiles, así como dos zonas de carbón, una en la parte inferior y otra en la parte media superior. El ambiente deposicional inferido es deltáico, con un componente costero pantanoso y otro fluvial. Dichas Formaciones subyacen en concordancia a la Formación Simón, de edad batoniana media-tardía, constituida por $\sim 270 \mathrm{~m}$ de subarcosas y limolitas dispuestas en estratos delgados y gruesos; el ambiente deposicional inferido es transicional (zona de playa). La Formación Simón subyace concordantemente a la Formación Otatera, de edad tardi-batoniana, consistente en $\sim 170 \mathrm{~m}$ de coquinas de pelecípodos con intercalaciones de estratos calcáreos de espatita; el ambiente deposicional inferido es nerítico somero, con un componente subordinado de playa. La unidad anterior subyace en concordancia a la Formación Yucuñuti, de edad mesocalloviana, constituida por $\sim 118 \mathrm{~m}$ de areniscas finas, coquinas, limolitas y biomicritas que portan pelecípodos y gasterópodos; el ambiente inferido es transicional (llanuras de inundación, laguna costera y zona nerítica somera); a esta formación le sobreyace en discordancia la Caliza con "Cidaris" del Oxfordiano.

2. La asociación florística continental del Jurásico Medio identificada en el área del río Numí, región de Tlaxiaco, Oaxaca estuvo formada principalmente por frondas y conos de cicadofitas de las especies Zamites oaxacensis Wieland, Z. lucerensis Wieland, Williamsonia netzahualcoyotlii Wieland, Ptilophylum acutifolium Morris y restos de helechos, con ausencia de equisetales y coniferofitas. Esta vegetación continental fósil se desarrolló en un clima cálido y húmedo por la abundancia de cicadofitas y helechos, así como la ausencia de ginkgofitas y coníferas. La paleoflora mesojurásica así constituida, cuyos taxa presentan una amplia distribución en la región del centro-sur de México y norte de América Central y el Caribe, lo cual evidencia una extensa provincia donde se desarrollaron cicadofitas y helechos en un clima cálido y húmedo. A su vez, la fauna de invertebrados consiste de moluscos marinos, entre ellos están pelecípodos de las especies Lucina cf. L. bellona D' Orbigny, 1850, Astarte sp., Vaugonia (Vaugonia) v-costata (Lycett) mexicana Alencáster, 1963, Trigonia (Indotrigonia) impressa Broderip, 1828, Eocallista imlayi Alencáster, 1963, Crenotrapezium hayami Alencáster, 1963, Pleuromya sp., Lucina bellona D’Orbigny, 1850, 
A

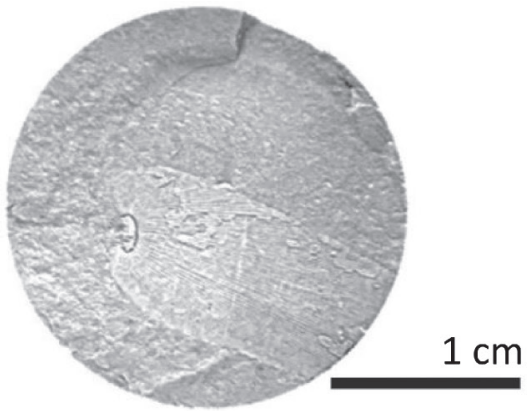

C

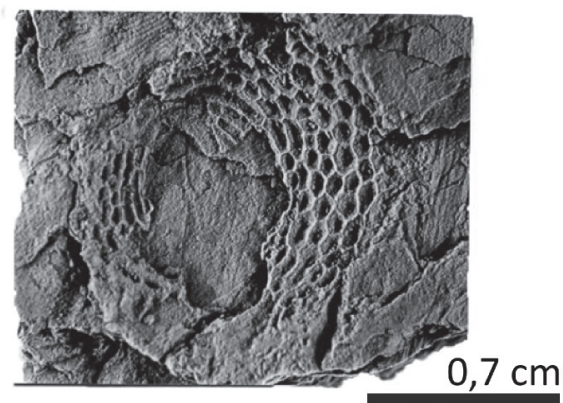

E
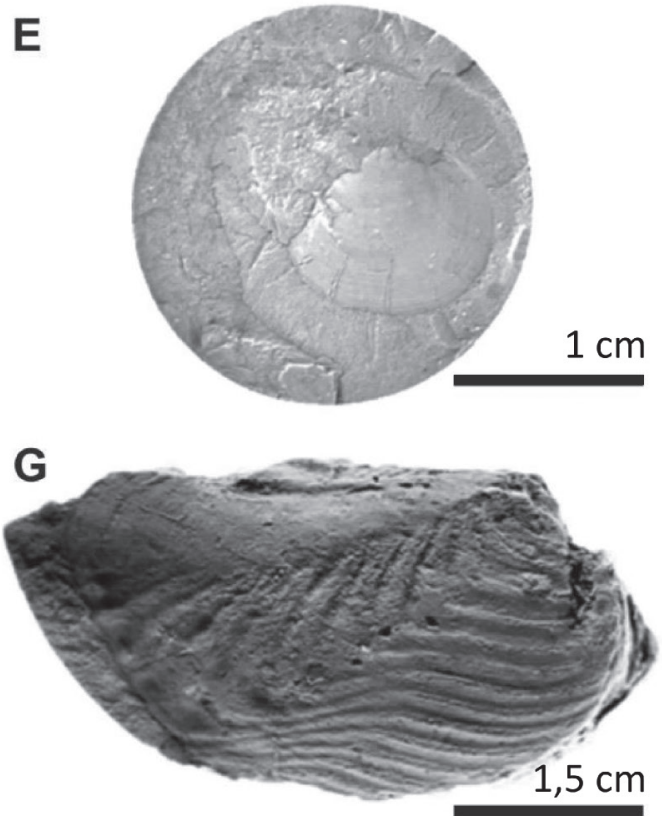

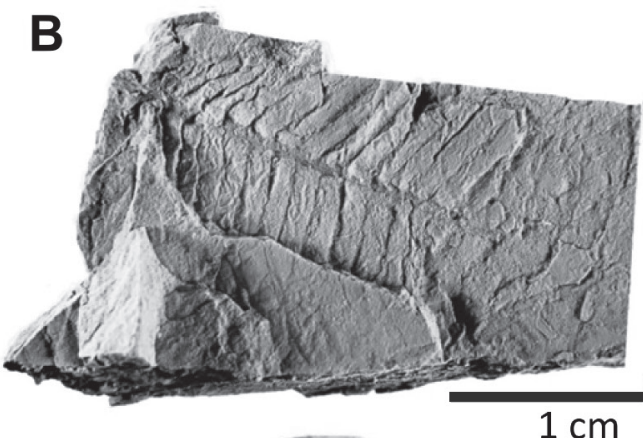

D

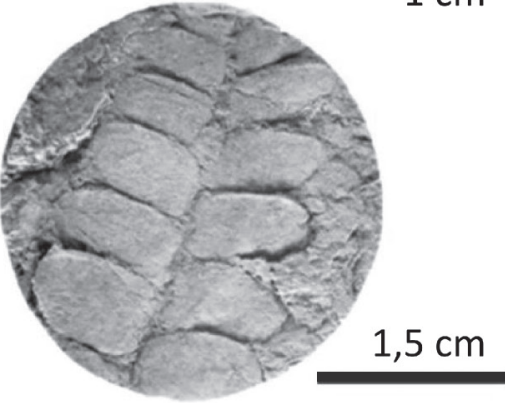

$\mathbf{F}$

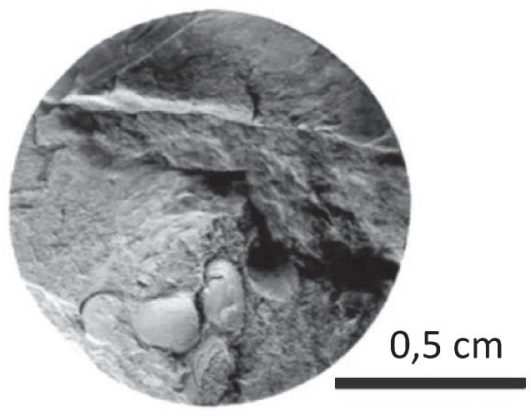

H

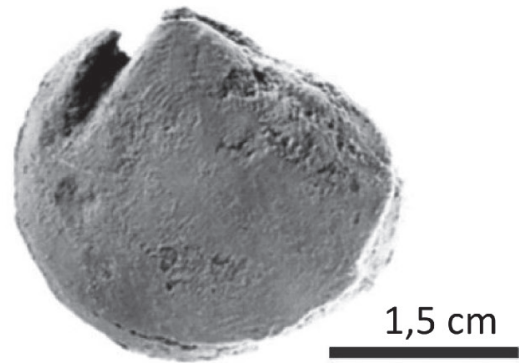

Fig. 13: Ejemplares recolectados en las Formaciones Zorrillo/Taberna. A) Zamites oaxacencis, B) Zamites lucerensis, C) Williamsonia netzahualcoyotlii, D) Ptilophyllum acutifolium, E) Lucina cf. L. bellona, F) Astarte sp., G) Vaugonia (Vaugonia) vcostata var. mexicana, H) Trigonia (Indotrigonia) impressa. 

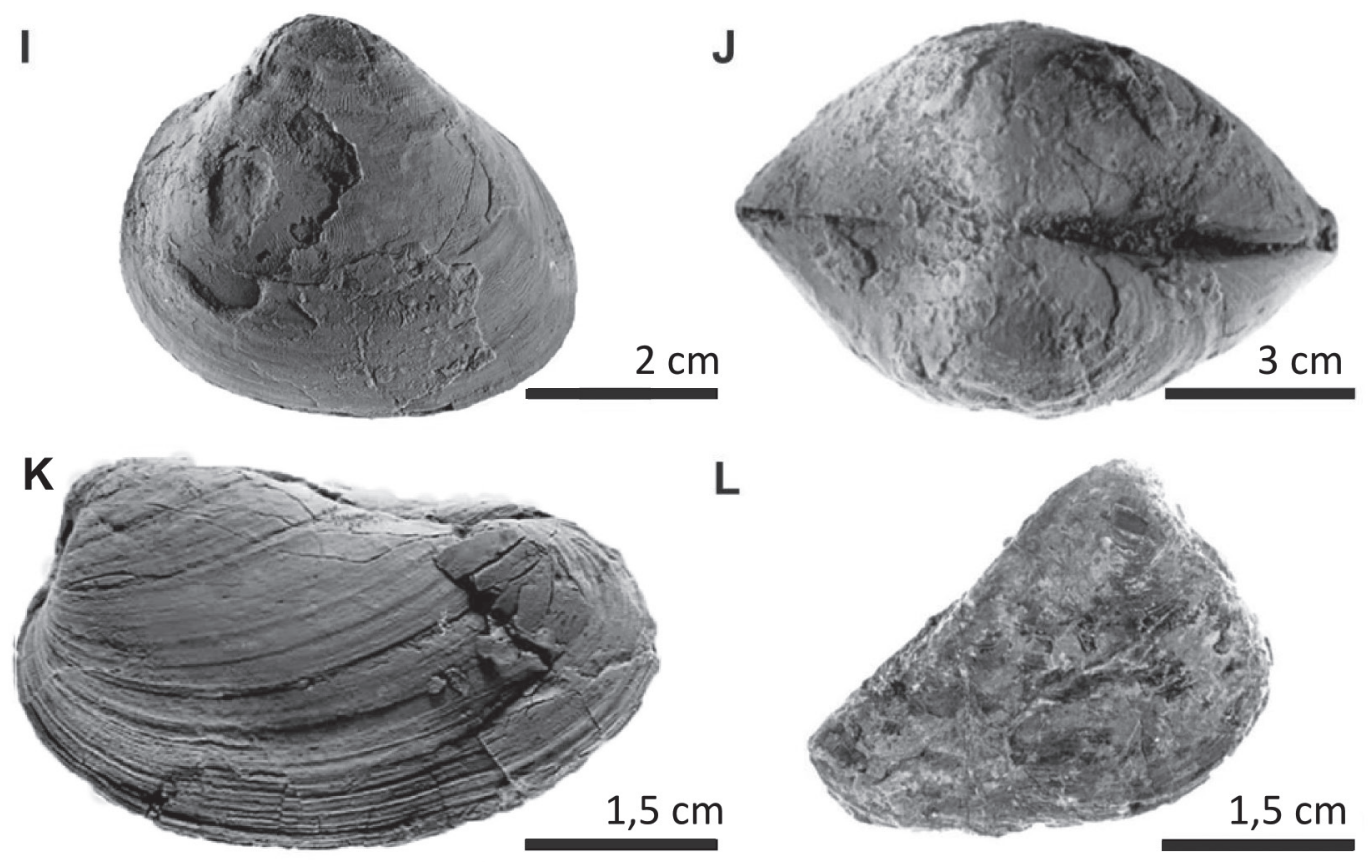

M

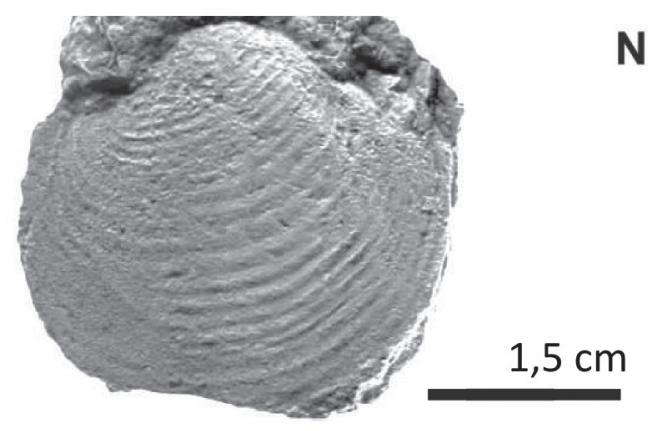

$\mathbf{N}$

$\tilde{\mathbf{N}}$
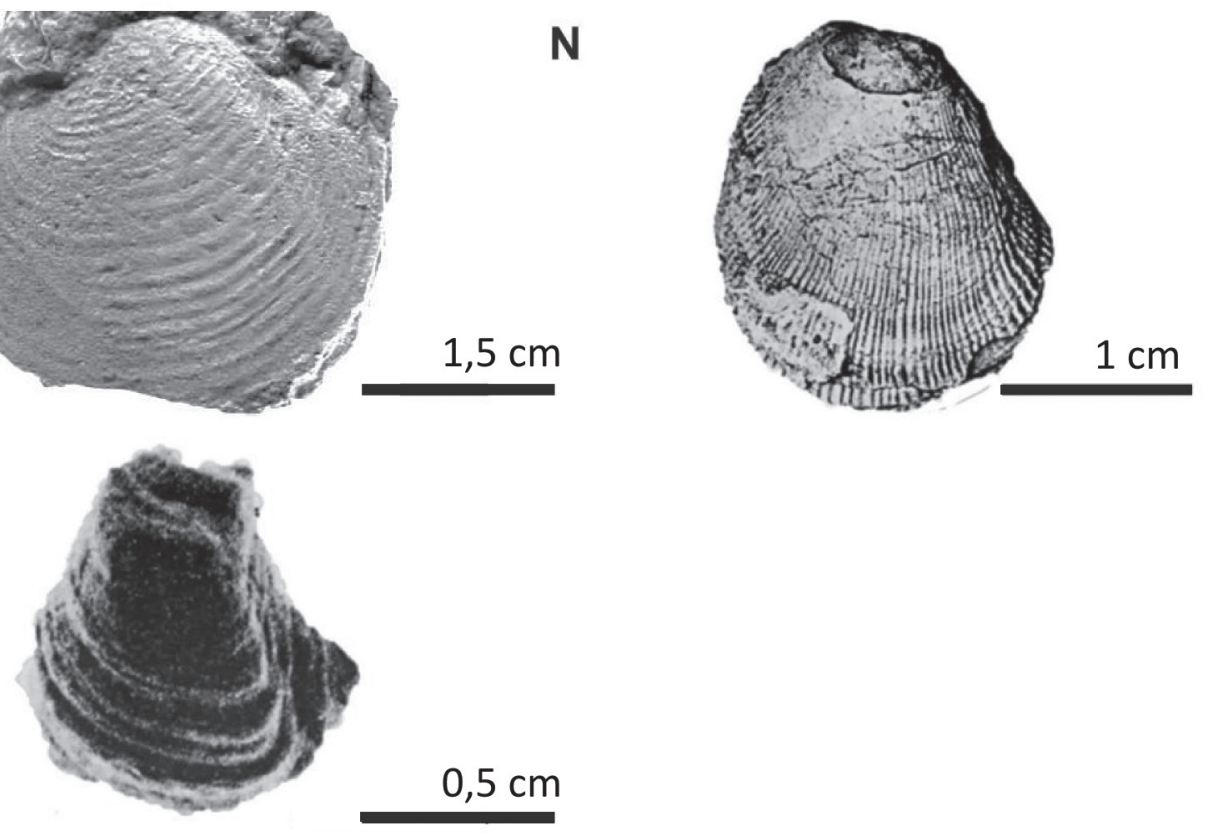

Fig. 13 (continuación): Ejemplares recolectados en la Formación Simón. I) y J) Eocallista imlayi, K) Pleuromya sp., L) Crenotrapezium hayami. Ejemplares recolectados en la Formación Yucuñuti. M) Lucina sp., N) Lima (Plagiostoma) sp., N) Gryphaea mexicana. 
Lima (Plagiostoma) sp., y fragmentos de gasterópodos, formando así una fauna mesojurásica mexicana diversa y abundante. Cabe destacar que Gryphaea mexicana Felix, 1891, se ha reportado también en el Oxfordiano de Tlaxiaco, Oaxaca y de Petlalcingo-Acatlán, Puebla (Alencáster, 1963; Alencáster y Buitrón, 1965).

3. Finalmente, se considera que la descripción detallada de las formaciones que constituyen al Grupo Tecocoyunca, es de facto un avance en la redefinición de las unidades mesojurásicas de la Región Mixteca [ver. NACSN, 2005, Art. 18, Remark (b)].

\section{AGRADECIMIENTOS}

Se agradece a las investigadoras del Instituto de Geología, UNAM Gloria Alencáster Ibarra y Alicia Silva Pineda su contribución en la identificación de moluscos y plantas respectivamente. Los doctores Francisco J. Grijalva y J. Ramón Torres-Hernández revisaron críticamente el manuscrito y aportaron numerosas sugerencias para mejorarlo, lo cual agradecemos profundamente. Asimismo agradecemos a la Biól. Greta M. Ramírez-Guerrero su apoyo en la preparación del texto y figuras.

\section{REFERENCIAS BIBLIOGRÁFICAS}

ALENCÁSTER, G., 1963: Pelecípodos del Jurásico del noreste de Oaxaca y noroeste de Guerrero.- Universidad Nacional Autónoma de México, Instituto de Geología, Paleontología Mexicana, 15: $1-52$.

ALENCÁSTER DE CSERNA, G. \& BUITRÓN, B. E., 1965: Fauna del Jurásico Superior de la región de Petlalcingo, estado de Puebla.- Universidad Nacional Autónoma de México, Instituto de Geología, Paleontología Mexicana, 21: 1-53.

ARAMBARRI, R. G. \& SILVA-PINEDA, A., 1987: Flora fósil de la región de Yucuquimi,
Oaxaca (Formación Rosario).- Rev. Soc. Mexicana de Paleontol. 1: 55-71.

ARECES-MALLEA, A., 1990: Piazopteris branneri (White) Lorch, helecho del Jurásico Inferior-Medio de Cuba.- Rev. Soc. Mexicana de Paleontol. 3(1): 26-40.

ASH, S. R., 1972: Piazopteris branneri from the Lower Jurassic, Egypt.- Rev. Paleobotany and Palynology, 13: 147-154.

BARRAGÁN, R., CAMPOS-MADRIGAL, E., FERRUSQUÍA-VILLAFRANCA, I., LÓPEZ-PALOMINO, I. \& TOLSON, G., 2010: Código estratigráfico norteamericano.- Universidad Nacional Autónoma de México, Bol. Inst. Geol. 117: 1-64.

BIRKINBINE, J. L., 1911: Exploration of certain iron ore and coal deposits in the state of Oaxaca.- Transactions of the American Institute of Mining and Metallurgical Engineers, 12:166-168.

BOGGS, S. Jr., 2009: Petrology of sedimentary rocks.- 600 págs. Cambridge, U.S.A., Cambrige University Press.

BRODERIP, W. J., 1828: Observations on the jaw of a fossils mammiferous animal, found in the Stonestfield Slate.- Zool. J. 3: 408-412.

BURCKHARDT, C., 1927: Cefalópodos del Jurásico Medio de Oaxaca y Guerrero.Bol. Inst. Geol. de México, 47: 2-108.

CARRASCO-RAMÍREZ, R. S., 1999: Bioestratigrafía de amonitas (CephalopodaAmmonoidea) del Bajociano y Calloviano de una porción de la Región Mixteca de Oaxaca.- 91 págs. Universidad Nacional Autónoma de México, México [Tesis Ph.D.].

CARRASCO-RAMÍREZ, R. S., 2003: Los ammonites del Calloviano de la Región Mixteca, Oaxaca, México.- Bol. Inst. Geol. de México, 56: 42-55. 
CASTILLO, A. y AGUILERA, J. G., 1895: Fauna fósil de la Sierra de Catorce, San Luis Potosí.- Comisión Geológica de México (Inst. Geol. de México), 1: 1-55.

CORTÉS-OBREGÓN, S., TORÓN, V. L., MARTÍNEZ, B. J., PÉREZ, L. J., GAMBOA, A. A., CRUZ, C. S. \& PUEBLA, P. M., 1957: La cuenca carbonífera de la Mixteca.- 191 págs. Banco de México, S.A., México.

CRAGIN, F. W., 1905: Paleontology of the Malone Jurassic formation of Texas.USGS Bull. 266: 52-172.

DELEVORYAS, T., 1966: Hunting fossils plants in Mexico.- Discovery (Connecticut), 2(1): 7-13.

DELEVORYAS, T., 1968: Jurassic Paleobotany in Oaxaca.- Geol. Amer. Soc. Guidebook for the Annual Meeting, Mexico City: 10-14.

DELEVORYAS, T., 1969: Glossopterid leaves from the Middle Jurassic of Oaxaca, Mexico.- Science, 165: 895-896.

DELEVORYAS, T., 1973: Investigations of North America Cycadeoids; Williamsonian cones from the Jurassic of Oaxaca, Mexico.- Rev. Palaeobotany and Palynology, 15: 27-42.

DELEVORYAS T. \& GOULD, R. E., 1971: An unusual fossil fructification from the Jurassic of Oaxaca, Mexico.- Bol. Amer. J. 58(7): 616-620.

DELEVORYAS T. \& PEARSON, C. P., 1975: Mexiglossa varia Gen. et sp. nov.; a new genus of glossopterid leaves from the Middle Jurassic of Oaxaca, Mexico.Palaeontographica, 154: 114-120.

DELEVORYAS, T. \& SRIVASTAVA, S., 1981: Jurassic plants from the department of Francisco Morazán, central Honduras.Rev. Palaeobotany and Palynology, 34: 345-347.
D'ORBIGNY, A., 1850: Prodrome de paléontologie stratigraphique universelle des mollusques et rayonées: faisant suite au Cours élémentaire de paléontologie et de géologie stratigraphiques (Vol. 2).- 444 págs. V. MASSON, París, DOI: 10.5962/bhl. title.45605.

ERBEN, H. K., 1956: El Jurásico Medio y el Calloviano de México.- Congreso Geológico Internacional, 20 ${ }^{\mathrm{a}}$. Sesión, Universidad Nacional Autónoma de México, Instituto de Geología, Publicación Especial: 140.

FEISTMANTEL, O., 1877: Jurassic (Liassic) flora of the Rajmahal Hills.- Paleontologia Indica, 2: 3-80.

FELIX, J., 1891: Versteinerungen aus der Mexicanischen Jura und Kreide Formation.- Palaeontographica, 37: 140-199.

FINKL, C. W. JR., 1988: The encyclopedia of field and general geology.- 911 págs. Van Nostrand Reinhold, New York.

FOLK, R. L., 1974: Petrology of sedimentary rocks.- 190 págs. Texas, Hemphill Publishing Company, EUA.

GUZMÁN, E. J., 1950: Geología del noreste de Guerrero.- Bol. Asoc. Mexicana de Geólogos Petroleros, 2: 95-156.

HOWARD, J. D. \& REINECK, H..E., 1981: Depositional facies of high-energy beach to offshore sequence: Comparison with low-energy sequence.- Amer. Assoc. of Petroleum Geologists Bull. 65: 807-830.

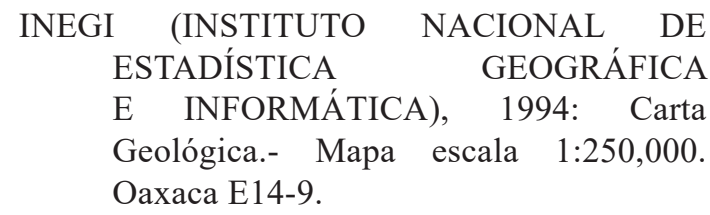


INEGI (INSTITUTO NACIONAL DE ESTADÍSTICA GEOGRÁFICA E INFORMÁTICA), 2000: Carta Topográfica.- Mapa escala 1:50,000. Tlaxiaco E14D34.

LÓPEZ-TICHA, D., 1985: Revisión de la Estratigrafía y potencial petrolero de la Cuenca de Tlaxiaco.- Bol. Asoc. Mexicana de Geólogos Petroleros, 37: 49-92.

McCOY, F., 1847: On the fossil and zoology of the rocks associated with the coal of Australia.- Annals and Magazine of Nat. Hist. 20: 145-157.

MENESES-ROCHA, J. J., MONROY-AUDELO, M. E. \& GÓMEZ-CHAVARRÍA, J. C., 1994: Bosquejo paleogeográfico y tectónico del Sur de México durante el Mesozoico.- Bol. Asoc. Mexicana de Geólogos Petroleros, 44(2): 18-45.

MORÁN-ZENTENO, D. J, CABALLERO, M. C. I, SILVA, R. G, ORTEGA, G. B. \& GONZÁlEZ, T. E., 1993: JurassicCretaceous paleogeographic evolution of the northern Mixteca terrane, southern Mexico.- Geofísica Int. 32: 453-473.

MORRIS, J., 1840: Memoir to Illustrate a Geological Map of Cutch (Grant, C. W.).- Transactions of the Geol. Soc. 5: 289-329.

\section{NACSN (NORTH AMERICAN COMMISSION} ON STRATIGRAPHIC NOMENCLATURE), 2005: North American Stratigraphic Code.- Bull. Amer. Assoc. of Petroleum Geologist, 89: 1547-1591.

OCHOTERENA-FUENTES, H., 1960: Variación intraespecífica en Parathyridina mexicana n. sp. Terebratúlido del Oxfordiano de México.- Paleontol. Mexicana, 9: 1-40.
OJEDA-RIVERA, J., 1975: Revaluación geoeconómica de los depósitos de carbón del área de Tezoatlán, Oaxaca.- Rev. Geomimet, 79: 21-40.

ORTEGA-GUTIÉRREZ, F., 1978: Estratigrafía del Complejo Acatlán en la Mixteca Baja, estados de Puebla y Oaxaca.- Rev. Inst. Geol. 2: 112-131.

ORTIZ-MARTÍNEZ, E. L., VELAZCO DE LEÓN, M. P., SALGADO-UGARTE, I. \& SILVA-PINEDA, A., 2013: Clasificación del área foliar de las gimnospermas fósiles de la zona norte de Oaxaca, México.- Rev. Mexicana de Cien. Geol. 20(10): 150-158.

PEARSON, C. P., 1976: The Middle Jurassic flora of Oaxaca, Mexico.- 145 págs. University of Texas, EUA [Tesis Ph.D.].

PEARSON, C. P. \& DELEVORYAS, T., 1982: The Middle Jurassic of Oaxaca, Mexico.Palaeontographica, 180: 82-119.

PÉREZ-IBARGÜENGOITIA, J. M., HOKUTO, C. A. \& DE CSERNA, Z., 1965: Reconocimiento geológico del área Petlalcingo-Santa Cruz, Municipio de Acatlán, estado de Puebla.- En: DE CSERNA, Z. \& HOKUTO-CASTILLO, A. (eds): Estratigrafía y paleontología del Jurásico Superior del estado de Puebla.- 22 págs. Inst. Geol., México.

RAMÍREZ, S., 1882: Estudio de unos ejemplares de carbón mineral procedentes del Distrito de Tlaxiaco en el Estado de Oaxaca.Anales del Ministerio de Fomento de la República Mexicana, 7: 108-113.

READING, H. G., 1996: Sedimentary Environments: Processes, Facies and Stratigraphy [3a ed.].- 704 págs. WileyBlackwell, EUA. 
REINECK, H. E. \& SINGH, I. B., 1980: Depositional Sedimentary Environments.549 págs. Springer-Verlag, EUA.

SANDOVAL, J. \& WESTERMAN, G. E. G., 1986: The Bajocian (Jurassic) ammonite fauna of Oaxaca, Mexico.- J. Paleontol. 60: 1220-1271.

SAPORTA, G., 1891: Paléontologie française ou description des fossiles de la France; plantes jurassiques.- Paris, Masson, 4: 547.

SCANU, G. G., KUSTATSCHER, E. \& PITTAU, P., 2012: The Jurassic plant fossils of the Lovisato Collection: preliminary notes.Bollettino della Società Paleontologica Italiana, 51: 71-84.

SCANU, G. G., KUSTATSCHER, E. \& PITTAU, P., 2013: Jurassic plants of Sardinia: An overview with new data.- Giornate di Paleontologia XIII edizione, Perugia, 1-2.

SGM (SERVICIO GEOLÓGICO MEXICANO), 2000.- Mapa escala 1:50,000, Carta Geológico-Minera Tlaxiaco, E32-D34.

SILVA-PINEDA, A., 1970: Plantas fósiles del Jurásico Medio de la región de Tezoatlán, estado de Oaxaca.- Soc. Geol. Mexicana, Libro guía de la excursión México-Oaxaca: 129-153.

SILVA-PINEDA, A., 1978a: Paleobotánica del Jurásico de México.- Paleontol. Mexicana, 44(1): 1-13.

SILVA-PINEDA, A., 1978b: Plantas del Jurásico medio del sur de Puebla y noroeste de Oaxaca.- Paleontol. Mexicana, 44(3): 27-56.

SILVA-PINEDA, A., 1984: Revisión taxonómica y tipificación de las plantas Jurásicas colectadas y estudiadas por Wieland (1914) en la región de El Consuelo, Oaxaca.Paleontol. Mexicana, 49: 104.
SILVA-PINEDA, A., 1990: Flora Fósil del Jurásico Medio de la Región de Chalcatongo en el suroeste del estado de Oaxaca.- Rev. Soc. Mexicana de Paleontol. 2(2): 7-15.

SILVA-PINEDA, A. \& GONZÁLEZGALLARDO, S., 1984a: Tafoflórula jurásica de la región de Chilpancingo-Tlapa, en el noreste del estado de Guerrero, México.- Memoria III Congreso Latinoamericano de Paleontología, México D.F.: 200-206.

SILVA-PINEDA, A. \& GONZÁLEZGALLARDO, S., 1984b: Algunas Bennetittales (Cycadophyta) y Coniferales (Coniferophyta) del Jurásico Medio del área de Cualac, Guerrero.- Rev. Inst. Geol. 7(2): 244-248.

SILVA-PINEDA, A., BUITRÓN, B. E. \& CARRASCO, R. R., 1986a: Bioestratigrafía del Jurásico de la región de Tlaxiaco, Oaxaca.- VIII Convención Geológica Nacional, Sociedad Geológica Mexicana, México D.F.: 84.

SILVA-PINEDA, A, BUITRÓN, B. E. \& CARRASCO, R. R., 1986b: Consideraciones paleoecológicas de las formaciones Zorrillo-Taberna (?AalenianoBatoniano) en la región de Tlaxiaco, Oaxaca.- VI Coloquio sobre Paleobotánica y Palinología, México D.F.: 45.

SILVA-PINEDA, A. \& ARAMBARRI, R G., 1991: Flora Jurásica de San Andrés Yutatío en el noroeste de Oaxaca.- Bol. Soc. Geol. Mexicana, 4: 57-61.

STACH. E., 1975: Coal Petrology.- 428 págs. Gebrüder Borntraeger, Berlin.

TATSCH, J.H., 1980: Coal Deposits.- 590 págs. Tatsch Associates, Massachusetts. 
THOMAS, H., 1911: The Jurassic flora of the Cleveland District of Yorkshire.- J. Geol. Soc. of London, 69: 223-251.

VAKHRAMEEV, V. A., 1956: Jurassic floras of the URSS.- Birbal Sahni Institute of Palaeobotany, Lucknow, 14(1-13): 118-123.

VAKHRAMEEV, V. A. \& LEBEDEV, E. L., 1985: Jurassic floras and climate of Pacific URSS.- 7 págs. Special paper International Geologic Correlation Program Project 171: Circum Pacific Jurassic. Jurassic climate of western Pacific area.

WEBBER, P. J., 1961: Phlebopteris branneri from the Western desert of Egypt.- Annals and Magazine of the Natural History, 4(37): 7-10.

WESTERMANN, G. E. G., 1983: The Upper Bajocian and Lower Bathonian (Jurassic) ammonite Faunas of Oaxaca, Mexico and west Thetyan affinities.- Universidad Nacional Autónoma de México, Instituto de Geología, Paleontología Mexicana 46: 1-63.

WESTERMANN, G. E. G., 1984: The Late Bajocian Duashnoceras association (Jurassic Ammonitina) of Mixtepec in Oaxaca, México.- Congreso Latinoamericano de Paleontología, Oaxtepec, Morelos, México: 192-198.

WIELAND, G. R., 1909: The Williamsonians of the Mixteca Alta.- Botanical Gazette, 48:427-411.

WIELAND, G. R., [1914-1916]: La flora liásica de la Mixteca Alta.- Bol. Inst. Geol. de México, 31: 1-162.

WIELAND, G. R., 1926: The El Consuelo Cycadeoids.- Botanical Gazette, 81: 72-86. 